\title{
Modelling coral calcification accounting for the impacts of coral bleaching and ocean acidification
}

\author{
C. Evenhuis ${ }^{1,2}$, A. Lenton ${ }^{1}$, N. E. Cantin ${ }^{3}$, and J. M. Lough ${ }^{3}$ \\ ${ }^{1}$ CSIRO Oceans and Atmosphere Flagship, Hobart, Tasmania, Australia \\ ${ }^{2}$ Plant Functional Biology and Climate Change Cluster, Faculty of Science, University of \\ Technology Sydney, Sydney, NSW 2007, Australia \\ ${ }^{3}$ Australian Institute of Marine Science, Townsville, Queensland, Australia \\ Correspondence to: C. Evenhuis (christian.evenhuis@uts.edu.au)
}

Received: 13 December 2013 - Published in Biogeosciences Discuss.: 6 January 2014

Revised: 2 February 2015 - Accepted: 17 February 2015 - Published: 5 May 2015

\begin{abstract}
Coral reefs are diverse ecosystems that are threatened by rising $\mathrm{CO}_{2}$ levels through increases in sea surface temperature and ocean acidification. Here we present a new unified model that links changes in temperature and carbonate chemistry to coral health. Changes in coral health and population are explicitly modelled by linking rates of growth, recovery and calcification to rates of bleaching and temperature-stress-induced mortality. The model is underpinned by four key principles: the Arrhenius equation, thermal specialisation, correlated up- and down-regulation of traits that are consistent with resource allocation trade-offs, and adaption to local environments. These general relationships allow this model to be constructed from a range of experimental and observational data. The performance of the model is assessed against independent data to demonstrate how it can capture the observed response of corals to stress. We also provide new insights into the factors that determine calcification rates and provide a framework based on wellknown biological principles to help understand the observed global distribution of calcification rates. Our results suggest that, despite the implicit complexity of the coral reef environment, a simple model based on temperature, carbonate chemistry and different species can give insights into how corals respond to changes in temperature and ocean acidification.
\end{abstract}

\section{Introduction}

Coral reefs are among the world's most biologically complex ecosystems; they support a diverse range of species and provide critically important ecosystem services such as food, resources for livelihoods and coastal protection. At present coral reefs face an unprecedented rate of environmental change in response to increasing atmospheric greenhouse gases and especially carbon dioxide $\left(\mathrm{CO}_{2} ; \mathrm{IPCC}, 2014\right)$. Two of the most immediate impacts of rising $\mathrm{CO}_{2}$ levels on coral reefs are increases in ocean temperatures and ocean acidification (Hoegh-Guldberg, 2011; Doney et al., 2009).

Globally the ocean plays a key role in slowing the rate of climate change by absorbing and sequestering approximately $25-30 \%$ of the annual anthropogenic atmospheric $\mathrm{CO}_{2}$ emissions (Le Quéré et al., 2013). When $\mathrm{CO}_{2}$ enters the ocean, a number of changes in sea water chemistry occur that are collectively referred to as ocean acidification (OA; Doney et al., 2009). For scleractinian corals, one of the most significant consequences of $\mathrm{OA}$ is the decrease in the concentration of carbonate ions $\left(\mathrm{CO}_{3}^{2-}\right)$. As coral's skeletons are made from the mineral phase of calcium carbonate, called aragonite, the saturation state of aragonite $\left(\Omega_{\mathrm{arg}}\right)$ is often related to rates of calcification. Studies have demonstrated that, as $\mathrm{CO}_{2}$ concentrations rise, the saturation state of aragonite $\left(\Omega_{\mathrm{arg}}\right)$ decreases and, in turn, the rate at which corals calcify declines (Schneider and Erez, 2006; Langdon, 2005; Pandolfi et al., 2011; Venn et al., 2013). Projections suggest that future rates of coral reef community dissolution may exceed rates of $\mathrm{CaCO}_{3}$ production (calcification), leading to net loss 
of reef framework and coral reef habitat within this century (Silverman et al., 2009; Hoegh-Guldberg et al., 2007).

As atmospheric greenhouse gas concentrations continue to rise, ocean temperatures will also continue to warm. Sea surface temperatures for coral reef areas of the tropical oceans have warmed $0.09^{\circ} \mathrm{C}$ per decade over the period 1950 to 2011 (Lough, 2012). Scleractinian corals are sensitive to increasing ocean temperatures. Experimental studies have shown that maximum calcification rates occur at an optimum temperature that is $2-3^{\circ} \mathrm{C}$ below the maximum temperature (Marshall and Clode, 2004) and that their calcification decreases more rapidly for warming above the optimum than for cooling. If the warming continues, the calcification rate continues to decline, ceasing at a temperature that is typically a few degrees above the seasonal maximum (Al-Horani, 2005; Cooper et al., 2008; Cantin et al., 2010). If the temperature exceeds this threshold, the corals lose their dinoflagellate symbiont, zooxanthellae, in a process known as thermal bleaching. Without the photosynthetic products provided by the symbiont, many essential physiological processes, such as calcification and reproduction, are repressed (Rodrigues and Grottoli, 2006; Carilli et al., 2009; Cantin et al., 2010). Observations suggest there has been an increase in the frequency and intensity of mass coral bleaching events due to thermal stress over recent decades, resulting in an estimated loss in hard coral cover of approximately $18 \%$ and a decline in the dominant populations at a rate of 1-2\% per year (Hoegh-Guldberg et al., 2011; Wilkinson, 2008).

Historically, the risk of coral bleaching due to extreme temperatures has been calculated using degree heating week (DHW) or degree heating month (DHM) metrics (e.g. Donner et al., 2005). As these metrics were built on empirical observations of bleaching they can be viewed as a statistical heuristic. Therefore, it is difficult to link DHW or DHM metrics to changes in biological function that result from stress, or to extend these metrics to include differential species response or to account for thermal adaptation. As a consequence, it is difficult to relate risk of bleaching given by the DHW metric to calcification rates (e.g. Buddemeier et al., 2008). Furthermore, there are a number of ways to estimate the thermal thresholds that underpin the DHW metric, and little consensus exists as to which approach is best suited to a given location. This is further complicated by the fact that the projected responses of coral reefs in some regions are highly sensitive to the way the thermal threshold is calculated (Donner, 2011), and that the distribution and severity of any coral bleaching event on individual coral reefs can be very heterogeneous (Baird and Marshall, 2002; Berkelmans et al., 2004).

Studies investigating the past and future response of corals usually focus either on the impact of increasing ocean temperatures leading to bleaching (e.g. Cantin et al., 2010; van Hooidonk et al., 2013; Frieler et al., 2013) or on ocean acidification (e.g. Ricke et al., 2013). Studies and models (e.g. Guinotte et al., 2003; Buddemeier et al., 2008; Silverman et al., 2009) that account for both the impact of ocean acidification and warming have not, as yet, mechanistically linked these two processes to calcification rates.

Here we present a new model that provides a unified description of coral calcification that links bleaching-related mortality, recovery from bleaching, and growth. The goal of this work is to provide a simple description of these processes that is motivated by the underlying physiological mechanisms and, where possible, to validate these against experimental observations. Our model provides a unified approach to modelling coral growth and health that captures differences between species and across locations. By taking into account ocean acidification and temperature, our model is able to better resolve the relative influence of these two stressors.

We start by acknowledging that coral reefs are very complex ecosystems that include a vast array of processes ranging from global scale climate systems down to wave action at the local reef scale, as well as the closely coupled interaction between hundreds of species of plants and animals. At present such a model at the reef scale is beyond the range of current observational coverage and theoretical understanding (e.g. Gustafsson et al., 2013). To overcome this limitation we do not aim to include all processes, but instead we a priori make a number of simplifications and parameterisations that allows a model to be constructed based on the response of coral calcification rate to changes in temperature and carbonate chemistry. We assume that, as a first approximation, the reef ecosystem is contingent on the calcium carbonate production from reef-building corals, and consequently the construction of the reef can be treated separately from the rest of the ecosystem. This "bottom-up" approach in turn allows the response of coral ecosystems to climate variability and change to be inferred from changes in the rate at which corals calcify.

The paper is structured as follows: the methods section describes the formulation of the model with its parameters estimated from synthesis of existing observational and experimental data. In the results section the new model is assessed against independent data and then used to explore the processes responsible for the linear relationship between average temperature and calcification rate observed by Lough and Barnes (2000). Finally, we compare this new model to existing models that combine ocean acidification and ocean warming, discuss the limitations of our modelling approach, and identify key areas for future research.

\section{Methods - model construction}

The goal of this model is to capture and use general, transferable relationships between growth, bleaching and calcification based on experiments and observations of corals from different locations and from different taxa to construct a 
model of coral calcification rate, shown in Eq. (1).

\begin{tabular}{|c|c|c|c|c|c|}
\hline & & $\begin{array}{l}\text { Aragonite } \\
\text { dependence }\end{array}$ & $\begin{array}{c}\text { Energy } \\
\text { available }\end{array}$ & Spec & \\
\hline $\begin{array}{c}\dot{G} \\
\text { Calcification } \\
\text { rate }\end{array}$ & $=\underset{\begin{array}{c}\text { Calcifcation } \\
\text { constant }\end{array}}{g_{\mathrm{C}}}$ & $\overbrace{\gamma(\Omega)}$ & $P_{\text {net }}\left(\bar{Q}^{\text {day }}, T\right)$ & constant $C_{\mathrm{sp}}$. & $\begin{array}{c}P_{\mathrm{H}} \\
\text { Population of } \\
\text { healthy coral }\end{array}$ \\
\hline
\end{tabular}

In our model the coral calcification rate represents an integrated indicator of annual energy investment, physiological performance and health of the coral colony (Cantin and Lough, 2014), which depends on the calcification constant $\left(g_{C}\right.$; Sect. 2.3.4); the aragonite saturation state response $(\gamma$; Sect. 2.1); energy available ( $P_{\text {net }}$; Sect. 2.2.4-2.2.7), which in turn depends on the light level through the daily insolation ( $\bar{Q}^{\text {day }}$, Sect. 2.3.2) and the temperature, $T$; the species of coral ( $C_{\mathrm{sp}}$ described in Sect. 2.3.3); and the population of healthy corals $\left(P_{\mathrm{H}}\right.$; Sect. 2.2.4). The modelled coral calcification rate (Eq. 1) integrates the influence of light (which drives net photosynthesis, $P_{\text {net }}$, and net calcification, $G_{\text {net }}$; Jokiel et al., 2014), temperature, carbonate chemistry, species-specific traits (growth rate and bleaching tolerance) and the health status of the coral population.

In Eq. (1) $\dot{G}$ has units of length $\times$ time $^{-1}, g_{C}$ has units of length $\times$ time $^{-1} \times$ area $^{-1}$ and can be viewed as a baseline calcification rate for a typical coral, and $P_{\mathrm{H}}$ has units of area; the remaining terms are dimensionless. If temperatures are in the range that the coral is acclimated to, and if carbonate chemistry is close to the historical average, these dimensionless terms are of order 1.

Commonalities in the temperature response among species have been extensively investigated using the metabolic theory of ecology (Dell et al., 2011; Brown et al., 2004) and dynamic energy budget (Nisbet et al., 2000) frameworks. In corals the temperature dependence is more complicated than other organisms as normal functioning relies on the symbiosis between the coral polyp and the dinoflagellate. This is reflected in the sophistication of coral models that describe host and symbiont behaviour (Muller et al., 2009; Gustafsson et al., 2013). To avoid modelling all of this complexity (and its inherent uncertainties), and to utilise the large body of published observational studies to construct our model, in this study we model the response of the holobiont (i.e. the coral and symbiont treated as a single entity) to changes in temperature and carbonate chemistry.

The following sections lead the reader through the formulation of each of the terms in Eq. (1), thereby explaining how each aspect of the model was formulated based on the synthesis of published observations. The model is outlined in the order of its development; Sect. 2.1 discusses calcification, Sect. 2.2 discusses changes in population, and Sect. 2.3 how the two are integrated. Within each subsection the model is ordered by the data sets used to determine the parameters. For example, in Sect. 2.3.3 species-level response is determined using bleaching data from the Great Barrier Reef, while in Sect. 2.3.4 the "thermal envelope" and the calcification constant are determined from global distribution of Porites cal- cification rates. The model can be outlined in many ways, but due to the multiple timescales that are involved, some jumps in the logic of the arguments are unavoidable. To aid the reader's understanding we have included a table of the equations, variables, and the determined and calculated values in the Appendix.

\subsection{Aragonite dependence $(\gamma)$}

Coral reefs are primarily composed of aragonite, a metastable crystal form of $\mathrm{CaCO}_{3}$ produced by hermatypic corals, with an orthorhombic system of acicular crystals. Calcification rates are commonly related to the aragonite saturation state, which is a measure of the inorganic solution equilibrium between solid aragonite and calcium and carbonate ions in solution. The dependence of calcification rate on the seawater carbonate system has been investigated (Erez et al., 2011; Pandolfi et al., 2011; Schneider and Erez, 2006; Putron et al., 2010; Shamberger et al., 2011; Jokiel et al., 2014), but a full understanding of the process is yet to be achieved. Experiments have shown that corals ingest seawater and are able to manipulate its carbonate chemistry within the subcalicoblastic medium to up-regulate the aragonite saturation state well above the surrounding seawater to enhance the precipitation of aragonite crystals (Al-Horani, 2005; Venn et al., 2013). Recent evidence indicates that, rather than the decrease in aragonite saturation states, it could be change in external seawater $\mathrm{pH}$ due to ocean acidification that disrupts the $\mathrm{pH}$ balance in the underlying calcifying tissue (calicoblastic epithelium) of reef-building corals, which in turn reduces the rate of calcification (Venn et al., 2013). This is consistent with models for calcification that treat the flux of protons from photosynthesis, calcification and exchange with external seawater in detail (e.g. Jokiel , 2011).

Our model employs an empirical relationship to describe how coral calcification relates to the carbonate chemistry of seawater on medium- to long-term timescales (weeks to annual increments of growth on decadal to centennial timescales). The model is not designed to capture diurnal changes, reef-scale hydrodynamics, boundary layers, biochemical pathways, etc. Instead it aims to describe the changes in "baseline" calcification by aggregating as many observational data as possible. The assumption is that diurnal swings and details like reef-specific hydrodynamics and differences in biology (such as population variability and life history) can be represented by their average values when a coarser scale is considered. This is analogous to the wellknown relationship between an organism's surface area and its volume in that it aims to extract a broad-scale trend from data that is superimposed with high variability. A plot of surface area to volume has large scatter coming from factors not captured by the relationship, such as the differences in fur or skin, and consequently has a low $R^{2}$ value. Although the relationship does not capture detailed species-specific processes, it is an incredibly useful tool for rationalising about biology 


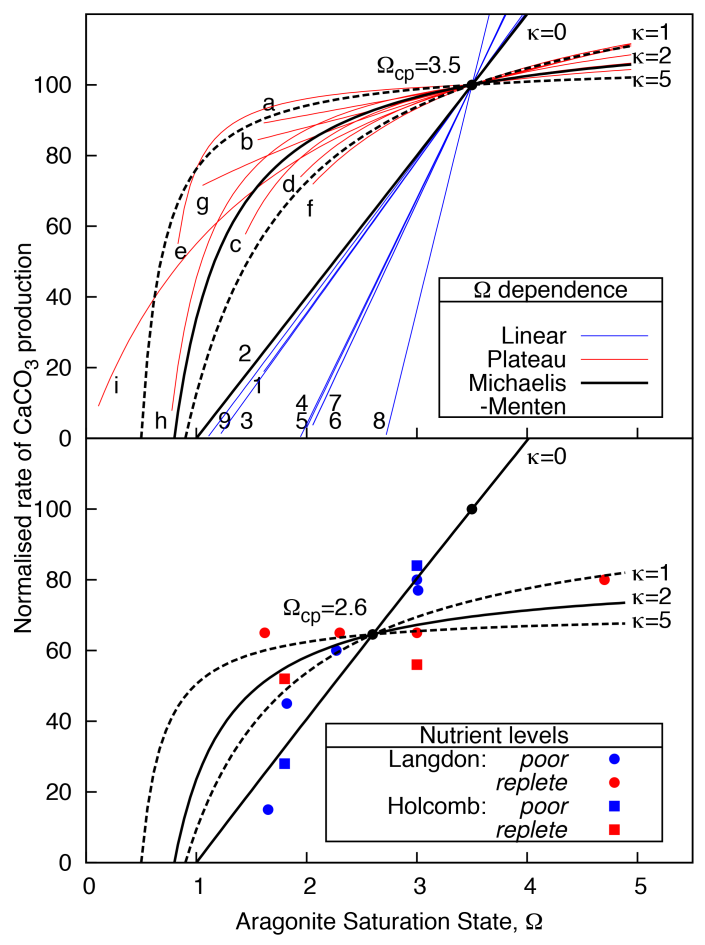

Figure 1. Comparison of the responses of coral to aragonite saturation state with the modified Michaelis-Menten curve from Eq. (2) plotted for linear response $(\kappa=0$, solid) and for plateaued responses ( $\kappa=1,2,5$, dashed, solid, dashed). Upper panel: curves are fitted to experimental data and normalised to present-day values of $\Omega=3.5$ and are plotted with $\Omega_{\mathrm{cp}}=3.5$. Lower panel: Results from the nutrient manipulation experiments of Holcomb et al. (2012) and Langdon (2005) are plotted with Eq. (2) for $\Omega_{\mathrm{cp}}=2.6$.

and serves as a starting point for more detailed models. It is with this goal in mind that we construct a functional form for the dependence of coral calcification on the carbonate chemistry of bulk seawater.

The next step is to choose a variable from which to construct this function. Increased concentration of dissolved $\mathrm{CO}_{2}$ results in a number of highly correlated changes in the seawater carbonate chemistry system. The concentrations of total dissolved inorganic carbon, $\mathrm{HCO}_{3}^{-}$and $\mathrm{H}^{+}$ all increase, while the concentration of $\mathrm{CO}_{3}^{2-}$ decreases. Jokiel et al. (2014; Fig. 8) illustrates this well by plotting normalised changes in the important carbonate system parameters throughout the daily calcification-dissolution cycle within a coral reef mesocosm. These parameters are highly correlated, so from a purely statistical viewpoint they are interchangeable in a regression-based model.

We chose to use aragonite saturation state for two reasons. Firstly, it has been widely used to model calcification rates, which makes it easier to compare this model to previously developed ones, and secondly, there is an existing paradigm through which to interpret the relationship; the calcification process is limited by the concentration of $\mathrm{CO}_{3}^{2-}$ ions. For the reasons discussed above it is clear that this is not the complete picture, but, like with any highly regulated, complex system, in some contexts a simple heuristic can very useful. Another of the seawater variables could have been chosen to fit the relationship. For example, another paradigm could be that the external $\mathrm{pH}$ of the seawater limits calcification of the coral.

To determine the functional form of $\gamma$ (Eq. 2), we examined experiments in which calcification rates were measured at constant temperature. The upper panel of Fig. 1 shows the relationship between calcification rate and aragonite saturation state for 18 experiments, from which two broad classes of responses are evident (an example of a more comprehensive list of experiments can be found in Table 2 of Erez et al., 2011). In the first class (drawn in blue) calcification declines linearly with aragonite saturation state, ceasing around $\Omega \approx 1$, while in the second class (drawn in red) the response remains plateaued. This response is relatively flat between $\Omega=3.5$ and 1.5 , followed by a steep decline in calcification when $\Omega<1$. The reason for the two responses is not yet understood (for a recent review see Chan and Connolly, 2013). Current hypotheses include differences in experimental techniques, differences between tropical and temperate corals, and time to acclimate to changes in seawater chemistry. The available experimental evidence suggests that the linear response could be related to nutrient concentrations (Pandolfi et al., 2011) as many reefs with low aragonite saturation state show high rates of coral calcification (e.g. Shamberger et al., 2011, 2014).

The observed linear and plateaued responses observed are fitted to a modified version of the Michaelis-Menten curve. This curve is widely used to describe biochemical reactions that are enzyme-mediated. Initially this curve increases linearly, after which it saturates and approaches an asymptotic value. The following function (Eq. 2) is used to fit both calcification responses:

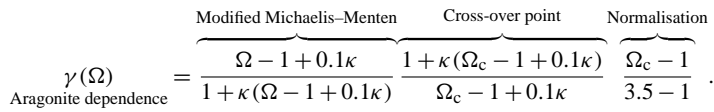

This functional form is controlled by two parameters: $\kappa$ determines the curvature, and $\Omega_{\mathrm{c}}$ sets the point at which curves with different values of $\kappa$ intersect. The upper panel of Fig. 1 plots the 18 experimental calcification rates, normalised so that at $\Omega=3.5$ the calcification rate is $100 \%$, this means that the cross-over point is also $\Omega_{\mathrm{c}}=3.5$. When $\kappa=0$ Eq. (2) simplifies to $\Omega-1 \frac{1}{3.5-1}$, which is the linear response that starts at $\Omega=1$ and is normalised to $100 \%$ at $\Omega=3.5$. In Fig. 1 it can be seen that by increasing $\kappa$ the curvature of the response increases, and the $0.1 \kappa$ term shifts the point at which the curve crosses the $x$ axis. This effect is most apparent for $\kappa=5$, for which the calcification rate ceases at $\Omega=0.5$. By fitting $\gamma$ to the plateaued experimental results we determined the plateaued class has a typical value of $\kappa=2$. 
Table 1. Sources of data for experimental results in Fig. 1

\begin{tabular}{|c|c|c|c|}
\hline \multicolumn{2}{|r|}{ Plateau } & \multicolumn{2}{|r|}{ Linear } \\
\hline $\mathrm{a}$ & Holcomb et al. (2012) & 1 & Holcomb et al. (2012) \\
\hline $\mathrm{b}$ & Langdon (2005) & 2 & Langdon (2005) \\
\hline $\mathrm{c}$ & Leclercq et al. (2000) & 3 & Schneider and Erez (2006) \\
\hline $\mathrm{d}$ & Leclercq et al. (2002) & 4 & Broecker et al. (2001) \\
\hline $\mathrm{e}$ & Ries et al. (2010) & 5 & Andersson et al. (2009) \\
\hline f & Marubini et al. (2001) & 6 & Albright et al. (2008) \\
\hline $\mathrm{g}$ & Marubini et al. (2008) & 7 & Erez et al. (2011) \\
\hline $\mathrm{h}$ & Gattuso et al. (1998) & 8 & Shaw et al. (2012) \\
\hline $\mathrm{i}$ & de Putron et al. (2011) & 9 & Ohde and Hossain (2004) \\
\hline
\end{tabular}

In the lower panel of Fig. 1 the results of Langdon (2005) and Holcomb et al. (2012) are used to determine the crossover point. These experiments measured calcification rates under both nutrient-poor and replete conditions. A linear response was observed in nutrient-poor conditions, whilst a plateaued response was observed in replete conditions. The results are normalised so that the linear response is $100 \%$ when $\Omega=3.5$. By fitting the curve for $\gamma$ with $\kappa=2$ to the nutrient replete results, the crossover point was determined to be $\Omega_{\mathrm{cp}}=2.6$.

In the upper panel of Fig. 1 there is a considerable spread in the results, some of which can be attributed to dissolution processes. Most of these experiments measured net calcification rate, which includes negative effects from processes such as dissolution. Although it is difficult to estimate the magnitude of the dissolution rate it is expected to be larger for in situ measurements than for laboratory experiments (Andersson and Gledhill, 2013).

One way to use Eq. (2) is to select between one of two possibilities; a linear $(\kappa=0)$ or plateaued $\left(\kappa=2\right.$ and $\left.\Omega_{\mathrm{cp}}=2.6\right)$ response. In this case it would be simpler to simpler to split Eq. (2) into two functions and for $\kappa$ to be a categorical variable. Eq. (2) was constructed to allow the Aragonite response to smoothly change between the two extremes by continuously varying $\kappa$ from 0 to 2 . In this way it is possible to test whether the dependence of calcification on ocean acidification is dynamic. In the remainder of the paper the data that the model is applied either have small changes in Aragonite saturation state (in which case the choice of response is irrelevant) or clearly demonstrate a linear response. Therefore, for the rest of the paper the data sets used the linear calcification response is used; however a plateaued response, or for that matter an intermediate response, could be substituted as desired.

\subsection{Modelling changes in population and health}

An important part of this model is its ability to describe the changes in the health and population of corals. As these changes are driven by how much energy from photosynthesis is available to a holobiont, it is necessary to first detail how photosynthesis is described in the model.

\subsubsection{Net photosynthesis $\left(P_{\text {net }}\right)$}

The model uses a qualitative representation of metabolism to correlate a number of traits. At the core of the model is a term that models the energy available as the net photosynthesis $\left(P_{\text {net }}\right)$ performed daily by the coral holobiont (Eq. 3).

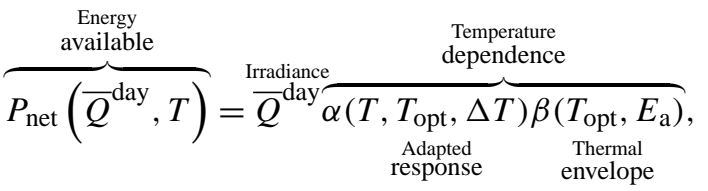

which depends on light, $\bar{Q}^{\text {day }}$, and temperature, $T$.

Net photosynthesis $\left(P_{\text {net }}\right)$, and hence the energy available for other processes, depends on the intensity of light, which is discussed in Sect. 2.2.2, and has been shown to correlate strongly with diurnal maximums in net calcification for corals (Jokiel et al., 2014). How much energy from photosynthesis is available to the coral also depends on temperature in two ways. The most apparent is the short-term response of corals to temperature fluctuations, which is determined by the temperature range it has adapted to ( $\alpha$; Sect. 2.2.3). Overlayed on this is the general tendency for the rate of biochemical reactions to increase with temperature ( $\beta$; Sect. 2.2.42.2.7)

Depending on the temperature there may be a surplus $\left(P_{\text {net }}>0\right)$ or a deficit of energy $\left(P_{\text {net }}<0\right)$. If the coral is healthy and conditions are favourable there is a surplus of energy $\left(P_{\text {net }}>0\right)$ that can be used to calcify, recover from stress, grow and reproduce. When conditions are unfavourable $\left(P_{\text {net }}<0\right)$ there is an energy deficit that stresses the coral, leading to bleaching and eventually death. The changes in the population and the stress state of the corals were discussed in the previous section (2.2).

\subsubsection{Irradiance $\left(\bar{Q}^{\text {day }}\right)$}

Our model assumes that corals are acclimated to their ambient light levels in order to avoid photo-damage, and that this acclimation takes place rapidly. Consequently, in the model we assume that the energy available to the corals depends directly on the daily solar insolation, i.e. the amount of solar radiation incident to the Earth's surface $\left(\mathrm{kW} \mathrm{m}^{-2}\right.$ day $^{-1}$; see equation in the Appendix).

Photosynthesis-irradiance $(P-I)$ curves for corals have been extensively studied, and how their parameters change with local light environment has been well established (Anthony and Hoegh-Guldberg, 2003a; Chalker et al., 1983; Dubinsky et al., 1984; Mass et al., 2007; Porter et al., 1984). These studies show that there is a strong decrease in the saturation intensity as ambient light levels decrease, which corresponds to an increase in the efficiency of photosynthesis. 
In addition, there are smaller decreases in maximum photosynthesis and respiration. Laboratory experiments in which corals were transferred between different light levels have also shown that the response is very rapid, i.e. it takes around a week for corals to adapt to a 10-fold change in light levels (Anthony and Hoegh-Guldberg, 2003b).

The change in saturation intensity can be understood in terms of a trade-off between gains from photosynthetic capacity and losses from photo-damage. If the saturation intensity is much higher than the maximum ambient intensity, then the rate of photosynthesis is lower than it could be, and decreasing the saturation intensity will increase the overall energy budget available for growth. However, if an organism's saturation intensity is below the maximum ambient intensity, then the cell is damaged as the photosynthetic apparatus will experience long periods of saturation. Therefore, the optimum setting for the saturation intensity will be approximately the maximum ambient intensity. This line of reasoning has been used in models of phytoplankton (Geider et al., 1997).

These assumptions mean that, in the model, corals are never light-saturated (always on the linear part of the $P-I$ curve) and that the net photosynthesis does not change with light levels. In other words, the exponential decrease in light that occurs with depth is offset by gains in photosynthetic efficiency from photo-acclimation. Clearly there are limits to this assumption as there will be a minimum level of light needed for photosynthesis. Nevertheless, there is evidence that this assumption holds when considering the community average of a coral living in typical reef conditions. For example, Mass et al. (2007) reported constant rates of photosynthesis and calcification at 5 and $10 \mathrm{~m}$ depths despite a $50 \%$ reduction in ambient light levels, and Hennige et al. (2008) demonstrated that Porites lutea from two sites and multiple depths regulates how much light is absorbed in order to maintain a constant load on its photosystem.

\subsubsection{The adapted temperature response $(\alpha)$}

The adapted temperature response $(\alpha)$ describes how symbiosis in coral is affected by temperature fluctuations on daily to monthly timescales. Although the shape of the adapted response is general, the adapted low $\left(T_{\mathrm{lo}}\right)$ and high temperatures $\left(T_{\mathrm{hi}}\right)$ depend on reef location. The shape of the adapted response is based on experimental observations of a range of processes, including photosynthesis (Jones et al., 1998), calcification (Al-Horani, 2005; Jokiel and Coles, 1977), growth (Edmunds, 2005), reproduction (Jokiel and Guinther, 1978) and respiration (Edmunds, 2008). All of these traits exhibit a common behaviour; the rate reaches a maximum at an optimum temperature and steeply decreases to zero on either side to define the adapted temperature range. The correlation between these biological processes suggests that they depend on the energy produced by the symbionts.
Mathematically, $\alpha$ (in Eq. 4) is constructed as a piecewise smooth combination of a cubic polynomial and a constant:

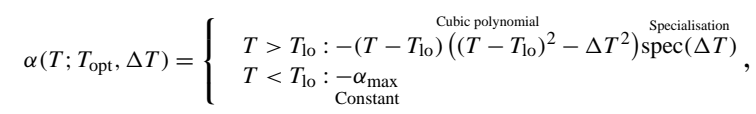

where

$T_{\mathrm{lo}}=T_{\mathrm{opt}}-\frac{1}{\sqrt{3}} \Delta T$

$T_{\mathrm{hi}}=T_{\mathrm{lo}}+\Delta T$.

The specialisation term, $\operatorname{spec}(\Delta T)$, describes changes due to thermal specialisation. As the specialisation term does not affect the shape of $\alpha$ (it only changes its magnitude) the detailed discussion of this term is deferred until Sect. 3.3.1.

The adapted response function depends on only the adapted range, which can be expressed as $\left(T_{\mathrm{lo}}, T_{\mathrm{hi}}\right)$ or $\left(T_{\mathrm{opt}}, \Delta T\right)$. The maximum of $\alpha$ is at $T_{\mathrm{opt}}$, and is positive between $T_{\mathrm{hi}}$ and $T_{\mathrm{lo}}$. For temperatures in the adapted range corals grow, calcify, reproduce and maintain healthy photosynthetic symbiosis, whilst outside of this range bleaching and mortality occur. Consistent with observations, the magnitude of the slope at $T_{\mathrm{hi}}$ is twice that at $T_{\mathrm{lo}}$.

Fig. 4 shows the fit of the adapted range $(\alpha)$ functional form to the experimental measurements of calcification rate (Al-Horani, 2005). Other researchers have modelled the temperature response of corals with cubic polynomials (e.g. Edmunds, 2005; Buddemeier et al., 2008). We found that the additional constraints imposed on the form of $\alpha$ aid in the interpretation and comparison of experimental results.

\subsubsection{Population states}

The population of a coral community is modelled as percentage cover, which is further classified into four states: healthy, recovering, stressed, and bleached. The four states come from reports of coral condition from the literature (e.g. ReefBase: http://www.reefbase.org). The states can be viewed as a qualitative measure of the health of the holobiont, capturing more quantitative measures such as density of the zooxanthellae.

The four states and the transitions between the states are shown schematically in Fig. 2 and are summarised as follows:

- Healthy corals grow and calcify at normal rates. When stressed, healthy corals turn pale.

- Pale corals have lost some of their zooxanthellae, and do not grow or calcify. When stressed, corals in the pale state transition to the bleached state, otherwise they transition to the recovering state.

- Bleached corals have lost the majority of their zooxanthellae, do not grow or reproduce, and face the risk of mortality. When stressed, corals in the bleached state die, otherwise they transition to the pale state. 
- Recovering corals are those that have only recently reacquired zooxanthellae after bleaching and therefore, although healthy in appearance, do not reproduce or calcify. When stressed, recovering corals turn pale, otherwise they return to healthy under normal conditions.

The transitions between the states are modelled by a system of first-order differential equations, and the rate of these transitions are modulated by a common temperature response, and by the general trends that are observed between species. The set of equations described in this section for bleaching and recovery are determined from the work of Jokiel and Coles (1977), who investigated calcification, bleaching and recovery rates of three Hawaiian coral species: Montipora verrucosa, Pocillopora damicornis and Fungia scutaria.

\subsubsection{Bleaching}

The transition of coral from healthy $\left(P_{\mathrm{H}}\right)$ to pale $\left(P_{\mathrm{P}}\right)$, to bleached $\left(P_{\mathrm{B}}\right)$, and finally to dead is given by the following first-order differential equation:

If $T<T_{\mathrm{lo}}$ or $T_{\mathrm{hi}}<T$ :

$\left(\begin{array}{c}\dot{P}_{\mathrm{H}} \\ \dot{P}_{\mathrm{R}} \\ \dot{P}_{\mathrm{P}} \\ \dot{P}_{\mathrm{B}}\end{array}\right)=\underset{\text { Bleaching constant }}{r_{\mathrm{B}}} P_{\text {net }}\left(\bar{Q}^{\text {nergy availabe }}, T\right)$

$\stackrel{\text { Species }}{C_{\mathrm{sp}}}\left(\begin{array}{cccc}+1 & 0 & 0 & 0 \\ 0 & +1 & 0 & 0 \\ -1 & -1 & +\frac{1}{2} & 0 \\ 0 & 0 & -\frac{1}{2} & +\frac{1}{4}\end{array}\right)\left(\begin{array}{c}P_{\mathrm{H}} \\ P_{\mathrm{R}} \\ P_{\mathrm{P}} \\ P_{\mathrm{B}}\end{array}\right)$,

where the constant $r_{\mathrm{B}}$ determines the timescale of the bleaching which is applicable for all locations and species, $C_{\mathrm{sp}}$ is the species constant, and $P_{\text {net }}$ determines is the energy available (negative when bleaching occurs). Importantly, the rate of bleaching is proportional to the species constant $\left(C_{\mathrm{sp}}\right)$; for example, faster-growing corals will bleach faster and have higher mortality, while slower-growing corals will be more resistant to bleaching, consistent with observations (Marshall and Baird, 2000). This differential response to temperature or $\left(C_{\mathrm{sp}}\right)$ can be understood in terms of an energy budget framework as a trade-off between growth and heat tolerance. There are a wide range of mechanisms and strategies that corals can use to mitigate the damage from bleaching. For example, a coral with significant stored energy reserves (lipids and proteins) and greater tissue biomass has increased survivorship following a bleaching event (Anthony et al., 2009; Thornhill et al., 2011). The coral and the symbiont may also employ anti-oxidants to deal with the increase in reactive oxygen species or express heat shock proteins to deal with the increased temperature (Baird et al., 2009), or corals may switch to feeding to meet the temporary decrease in autotrophic energy from photosynthesis (Houlbreque and Ferrier-Pages, 2009). Whatever the strategy a coral employs

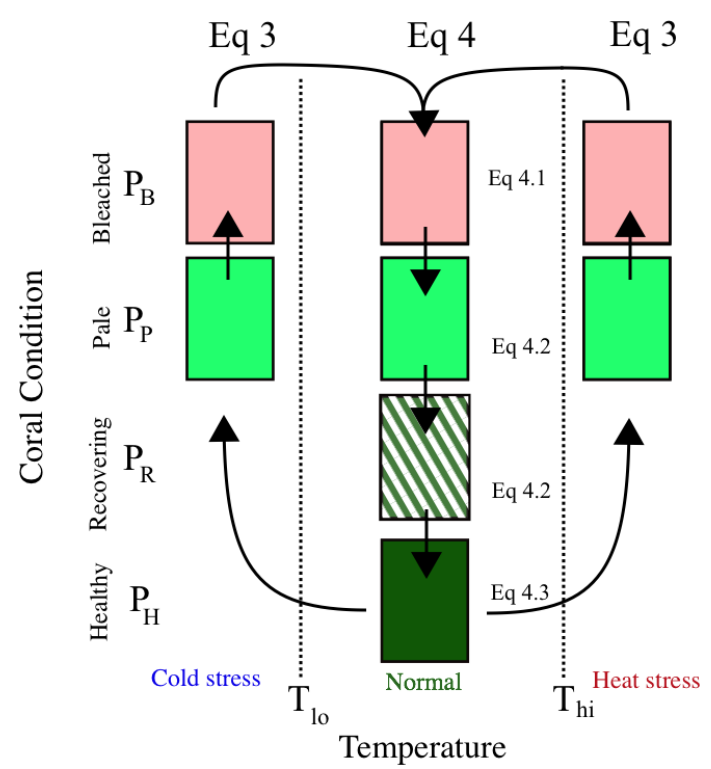

Figure 2. The four states of coral physiological health status in the model (healthy, recovering, pale, and bleached). The transitions between the four states are represented by arrows, and the size of the arrow gives an indication of the relative rates of the processes.

to defend against heat stress, it will divert energy that otherwise could have been allocated to growth and reproduction.

The transitions between the four coral states, shown schematically in Fig. 2, correspond to the entries in the $4 \times 4$ matrix in Eq. (5). The first row of Fig. 3 shows the fit of the adapted response curve to the measurements of $\mathrm{CaCO}_{3}$ calcification rate from Jokiel and Coles (1977). This allowed the adapted temperature range $\left(T_{\mathrm{lo}}, T_{\mathrm{hi}}\right)$ and the species constant $\left(C_{\mathrm{sp}}\right.$; full description in Sect. 3.3.3) to be determined for each coral. As long-term thermal adaptation plays a negligible role in these experiments, the thermal envelope was set to be $1(\beta \approx 1)$. The species parameter was defined to be 1.0 for $P$. damicornis. As the adapted range is the same for the three corals, $T_{\mathrm{opt}}$ the rates of the transition (healthy to pale, pale to bleached, bleached to dead) can be determined by fitting the model to the bleaching observations of $P$. damicornis. The agreement between the model and observation is very good, allowing the rate of the bleaching constant to be calculated as $r_{\mathrm{B}}=8 d^{-1}$. This in turn allows the species constants $M$. verrucosa $\left(C_{\mathrm{sp}}=2\right)$ and F. scutaria $\left(C_{\mathrm{sp}}=0.9\right)$ to be calculated.

\subsubsection{Recovery from bleaching}

After exposure to elevated temperatures, corals undergo a range of recovery processes (Fig. 2). When a coral recovers, any mortality ceases, symbiosis is re-established, reserves such as lipid stores are replenished, and the coral is repopulated with zooxanthellae. Again, these recovery processes are modelled using the following set of first-order differen- 
tial equations (Eq. 6), which differ from Eq. (5) with the addition of an additional recovering state $\left(\dot{P}_{\mathrm{R}}\right)$. This state follows observations of recently bleached corals that despite having a healthy appearance display suppressed or inhibited rates of calcification, growth and reproduction (Rodrigues and Grottoli, 2006). Figure 3 shows the comparison between the model output using Eqs. (6a) and (6b). Note that the modelling results include the recovering state $\left(P_{\mathrm{R}}\right)$, which was not reported in the experimental results of Jokiel and Coles (1977).

$$
\begin{gathered}
\text { If } T_{\mathrm{lo}}<T<T_{\mathrm{hi}}, \\
\left(\begin{array}{c}
\dot{P}_{\mathrm{H}} \\
\dot{P}_{\mathrm{R}} \\
\dot{P}_{\mathrm{P}} \\
\dot{P}_{\mathrm{B}}
\end{array}\right)=\underset{\begin{array}{c}
\text { Mortality } \\
\text { constant }
\end{array}}{r_{\mathrm{M}}}\left(\begin{array}{cccc}
0 & 0 & 0 & 0 \\
0 & 0 & 0 & 0 \\
0 & 0 & 0 & 0 \\
0 & 0 & 0 & -1
\end{array}\right)\left(\begin{array}{c}
P_{\mathrm{H}} \\
P_{\mathrm{R}} \\
P_{\mathrm{P}} \\
P_{\mathrm{B}}
\end{array}\right), \\
+\underset{\substack{\text { Recovery } \\
\text { constant }}}{r_{P_{\text {net }}\left(\bar{Q}^{\text {day }}, T\right)}^{\text {Energy available }}}\left(\begin{array}{cccc}
0 & +\frac{1}{2} C_{\mathrm{sp}} & 0 & 0 \\
0 & -\frac{1}{2} C_{\mathrm{sp}} & +C_{\mathrm{sp}} & 0 \\
0 & 0 & -C_{\mathrm{Sp}} & +8 / C_{\mathrm{sp}} \\
0 & 0 & 0 & -8 / C_{\mathrm{sp}}
\end{array}\right)
\end{gathered}
$$

Again, the form of the equation was determined by fitting to the results of Jokiel and Coles (1977), and the values of the continued mortality and recovery time constants were determined to be $r_{\mathrm{M}}=0.04 d^{-1}$ and $r_{\mathrm{R}}=0.2 d^{-1}$, respectively. The first term in Eq. (6) represents the continued risk of mortality that bleached corals face even when the temperature returns to the adapted range, and reflects the limited ability of corals to survive without zooxanthellae. This term is also proportional to the species constant $C_{\mathrm{sp}}$, which can be understood as capturing how slower-growing corals are more resilient to bleaching. The second term in Eq. (6) represents the recovery from bleaching as the coral returns from bleached to pale, pale to recovering, and finally to healthy. The bleached to pale transition term differs from the other terms, as it is inversely proportional to the species constant. This means that, in general, faster-growing corals react more negatively to bleaching (more rapid bleaching, increased risk of mortality when bleached and slower to re-establish symbiosis), the exception being that the transition from pale to healthy is more rapid in faster than in slower growing corals. At present, without additional data on recovery dynamics it is difficult to determine whether this is an artefact resulting from over fitting the uncertainties in the experimental data or whether this reflects an intrinsic difference between the biological processes that take place during recovery.

\subsubsection{Population growth constant $\left(r_{\mathrm{G}}\right)$}

Coral population growth is the slowest of the population changes in the model and is very difficult to determine empirically; therefore it is associated with large uncertainty. As the model uses coral cover, this term (Eq. 7) encompasses the growth of individual corals, natural mortality, the recolonisation of dead coral structures, reproduction and constraints on growth from the maximum habitat size.

If $T_{\mathrm{lo}}<T<T_{\mathrm{hi}}$,

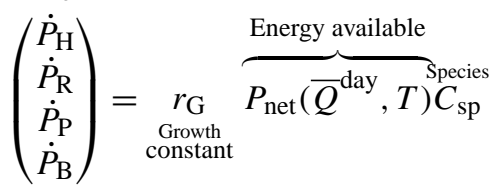

$$
\begin{aligned}
& +\overbrace{\left(K-P_{\mathrm{T}}\right)}^{\begin{array}{c}
\text { Logistic } \\
\text { botleneck }
\end{array}}\left(\begin{array}{cccc}
+1 & 0 & 0 & 0 \\
0 & 0 & 0 & 0 \\
0 & 0 & 0 & 0 \\
0 & 0 & 0 & 0
\end{array}\right)\left(\begin{array}{c}
P_{\mathrm{H}} \\
P_{\mathrm{R}} \\
P_{\mathrm{P}} \\
P_{\mathrm{B}}
\end{array}\right) .
\end{aligned}
$$

The term $\left(K-P_{\mathrm{T}}\right)$ is referred to as the logistic growth in ecological modelling, and serves to reduce the growth rate as the total population $\left(P_{\mathrm{T}}=P_{\mathrm{H}}+P_{\mathrm{R}}+P_{\mathrm{P}}+P_{\mathrm{B}}\right)$ approaches the carrying capacity $(K)$ of the location. In this work $K=1$ (i.e. $100 \%$ carrying capacity) assuming that the corals start at their maximum carrying capacity. However, there is scope to model external stressors that change the carrying capacity of a location, such as storm damage or sea-level rise, or the creation of habitat by allowing $K$ to vary temporally.

The range of values for the growth constants is large (Table 2), as there are many contributing factors, such as whether the measurements are taken under laboratory conditions that remove stressors that in situ coral observations record. While it is very hard to get a firm estimate of this parameter, we selected the value of the growth constant $\left(r_{\mathrm{G}}\right)$ to be $0.002 d^{-1}$ based on a synthesis of published studies (Table 2) that report the return of coral cover after disturbance such as bleaching.

\subsection{Integrating calcification and population changes}

In this section the terms that relate growth and calcification between species and across location are detailed. These terms appeared in the previous section and were either set to 1 or absorbed into other parameters when fitting the model to observations. These terms are now discussed and their parameters determined.

\subsubsection{Thermal specialisation $(\operatorname{spec}(\Delta T))$}

Thermal specialisation is a useful approach to tackle the problem of determining bleaching thresholds. Thermal bleaching thresholds are typically only a few degrees above and below local temperature extremes and do not take into account the variability in tolerance levels of diverse coral communities. From this observation two assumptions are drawn that are central to the model: firstly, that corals are able to adapt to their local temperature environment, which is described by the adapted response function $(\alpha)$, and secondly, that corals must derive some benefit that offsets the increased risk of bleaching that arises from having their thermal threshold close to the extremes of local temperature. The last observation motivates the inclusion of a reward for thermal specialisation within the model, while the first suggests a method for determining the thermal thresholds $T_{\mathrm{lo}}$ and $T_{\text {hi }}$. 
Table 2. Estimated growth constants for the corals after bleaching

\begin{tabular}{|c|c|c|c|}
\hline $\begin{array}{l}\text { Growth rate } \\
\left(r_{\mathrm{G}} ; d^{-1}\right)\end{array}$ & $\begin{array}{l}\text { Type of } \\
\text { experiment }\end{array}$ & Timescale & Reference \\
\hline 0.0200 & Reproduction in laboratory & Months & Jokiel and Coles (1977) \\
\hline 0.0100 & $\begin{array}{l}\text { Regen. of a bleached reef } \\
\text { (overlap with recovery) }\end{array}$ & Years & Diaz-Pulido et al. (2009) \\
\hline $0.0025-0.0010$ & Regen. of a bleached reef & Years & Brown and Suharsono (1990) \\
\hline 0.0020 & Regen. of a bleached reef & Years & Baker et al. (2008) \\
\hline 0.0020 & Regen. of a bleached reef & Years & Baker et al. (2008) \\
\hline $0.0015-0.0007$ & 10-20-year recovery estimate & Years & Coles and Brown (2007) \\
\hline 0.0010 & Regen. of a bleached reef & Years & Adjeroud et al. (2009) \\
\hline 0.0010 & Regen. of a bleached reef & Years & Ceccarelli et al. (2011) \\
\hline 0.0008 & Regen. of a bleached reef & Years & Halford and Caley (2009) \\
\hline
\end{tabular}

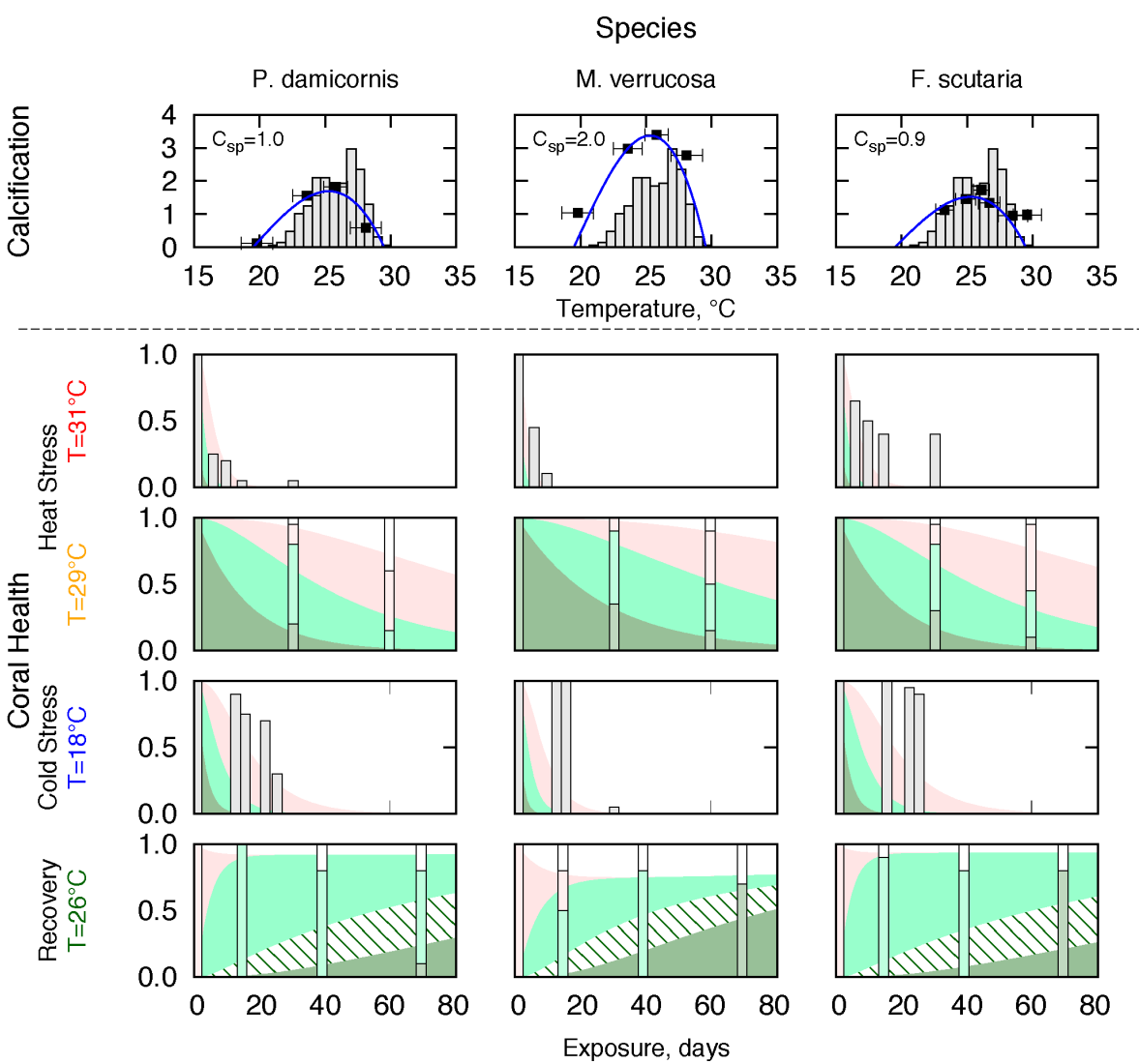

Figure 3. Comparison of the simulated results with those observed by Jokiel and Coles (1977). The first row is the observed calcification rates (box and whiskers), the histogram of temperatures (grey boxes) and the adapted response curve (blue line). The lower 4 rows show the observations of coral health as bars. When coral health was reported the bars are coloured as in Fig. 2, otherwise when only the total population was reported the bars are coloured grey. The model results are shown as continuous fill using the colour scheme of Fig. 2.

In the model, thermal specialisation is rewarded through the following term that appears in Eq. (4):

$\operatorname{spec}(\Delta T)=4 \cdot 10^{-4} \exp [-0.33(\Delta T-10)]$

The purpose of this term is to lower the adapted temperature response as the adapted range increases (see Fig. 8a).
This reduces the energy available to the coral and hence lowers calcification and growth rates and reduces the sensitivity of corals to bleaching. Although not explicitly modelled through using an energy budget, the correlated up- and downregulation of traits in the model can be rationalised as a resource allocation trade-off. In this case, a coral that is adapted 


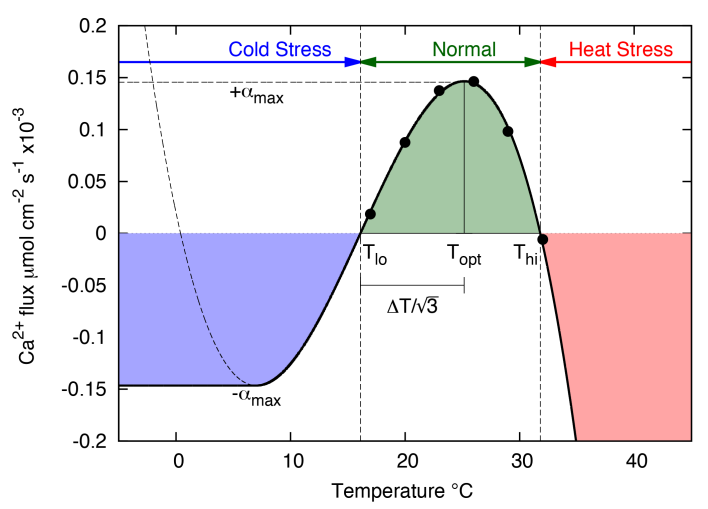

Figure 4. The functional form of adapted response $\alpha$ (thick black line) fitted to experimental data of Al-Horani (2005) (black circles). The adapted temperature range is shown in green and the temperatures at which heat stress and cold stress occur are shown in red and blue, respectively.

to a wide temperature range has undergone changes that allow it to deal with a wider range of temperatures, and this results in a decrease in growth-related traits.

The simplest way to achieve this from a mathematical standpoint is to conserve the area under the adapted response curve (i.e. to normalise the function $\alpha$ over the temperature $T_{\text {lo }}$ to $T_{\text {hi }}$ ). If the area under $\alpha$ were conserved, then the specialisation term would be $4 \times \Delta T^{-4}$. This would mean that, for corals from two sites where the temperature range at the first site is twice that of the second, the model would predict that the rates of growth and calcification at the first site would be half that of the second. This is a common choice for normalisation of reaction norms (see, for example, Gilchrist ,1995).

Although strict normalisation is attractive from a mathematical standpoint, it results in unrealistic behaviour. As it is inversely proportional to the adapted range, the adapted response curve decreases too slowly when the temperature range is large and increases too quickly when the temperature range is small. To address this problem the $\operatorname{spec}(\Delta T)$ term (Eq. 8) is designed to approximate strict normalisation around $10{ }^{\circ} \mathrm{C}$, but has more realistic behaviour at small and large adapted ranges. The coefficient in the exponential was determined by matching calcification rates to adapted temperature ranges.

\subsubsection{Determining the adapted temperature range ( $T_{10}$ and $T_{\mathrm{hi}}$ )}

The adapted temperature range can be estimated from historical temperature records by using the thermal specialisation term outlined in the previous section. The adapted range is found by maximising the calcification rate over a historical period by assuming that the corals have adapted to their local climate. Strictly speaking calcification is not a measure of Darwinian fitness. However, the simplicity of the model means that reproduction is not explicitly treated (reproduction is implicitly modelled by a logistic equation), which leaves calcification as the best available variable to serve as a proxy for Darwinian fitness.

Maximising the average calcification rate finds the best trade-off between the competing effects of bleaching (which favours a large adapted range) and thermal specialisation (which favours a small adapted range). Figure 6 illustrates this trade-off by showing how changes in the coral population (area) and calcification rate per area affect the changes in community calcification rate for three cases, when the adapted temperature is too wide, is just right, or is too narrow.

The first column shows what happens if the adapted range is too large. The histogram of temperatures falls entirely under the adapted temperature curve. Although no bleaching occurs and there is no drop in population due to thermal stress, the calcification rate is the lowest due to the thermal specialisation penalty. The third column shows what happens if the adapted range is too small. A significant fraction of the temperature histogram falls above $T_{\text {hi }}$. Although the possible calcification rate is higher, the higher frequency and intensity of bleaching reduce the healthy population, which in turn reduces the total calcification. The second column shows the optimal temperature range, which strikes the balance between maintaining population and calcification rate. Some bleaching is tolerated in order to boost the potential calcification rates and maximise the total calcification.

The adapted range $\left(T_{\mathrm{lo}}\right.$ and $T_{\mathrm{hi}}$ ) can be determined on a per-location basis by maximising the total calcification rate. This is a very powerful tool that allows this model to be applied globally to either observational records or to climate model output. It will turn out that the species constant $C_{\mathrm{sp}}$ is the only remaining "free parameter" in the model. The other parameters, such as those controlling bleaching and growth, have set values from comparison to experiment, and these are globally defined; that is, the parameters get applied for all locations and species. The temperature thresholds are set from the historical temperature record for a location.

\subsubsection{Species response $\left(C_{\mathrm{sp}}\right)$}

Studies have identified the role of species as a confounding variable when comparing observations of corals. As discussed above, species-level differences in how corals grow and calcify and their sensitivity to bleaching are modelled through the species parameter $C_{\mathrm{sp}}$. In the model, fastergrowing corals are more sensitive to bleaching and have $C_{\mathrm{sp}}>1$, whilst corals that calcify and grow slower but are more resistant to bleaching are modelled as having $C_{\mathrm{sp}}<1$.

In the previous section, differences between species were captured in the model by the species constant $C_{\mathrm{sp}}$, which modulates the relative rates of key processes. A value for $C_{\mathrm{sp}}$ was found from direct measurements of the calcification rate, which in turn was used to infer the relative rates of growth, bleaching and recovery. Having established the form of rela- 
tionship, a value for $C_{\mathrm{sp}}$ can be determined from relative differences in a thermal performance curve for a growth-related trait (such as calcification) or from high-resolution bleaching observations. However, in many experiments detailed thermal performance data are not available, and similarly species distribution surveys are not available for reef communities.

To apply the model to a range of species it is necessary to have an estimate for the range of $C_{\mathrm{sp}}$ and typical values for faster and slower growing coral species. There a number of ways this information could be used to simulate a coral reef community. The most detailed would be to model each species found on a reef with its own $C_{\text {sp }}$. A practical approximation is to group corals into broad classes of slow, average and fast growers and to compare the changes in populations. An even coarser approximation is to select a representative value of $C_{\mathrm{sp}}$ for an entire reef based on its dominant species composition, which would enable the user to identify sensitive and tolerant reefs based upon the species composition of the reef.

In this section an estimate of the species constants of a wide range of coral species is derived from observations of the large-scale bleaching in 1998 on the Great Barrier Reef (GBR; Marshall and Baird, 2000). This allows the species of coral to be linked to the species constant $C_{\mathrm{sp}}$ and can serve as a guide when setting up the model for a specific coral reef. Figure 7 compares the bleaching observations to the model output for a range of species constants. Simulations were run with an adapted temperature range of $T_{\mathrm{lo}}=20.0$ and $T_{\mathrm{hi}}=30.6$, which was estimated from historical temperatures from the HadISST sea surface temperature (SST) data set (Rayner et al., 2003) and from bleaching events reported in ReefBase (http://www.reefbase.org). The model was run from 1 January 1998 to 12 March 1998 using in situ water temperature for Pelorus Reef (www.aims.gov.au). In Fig. 7 the value of the species constant varied from 0.2 to 4 to cover the observed range in bleaching responses. Although the agreement between observations and model output for the percentages of healthy and dead corals is generally good, the pale and bleached categories systemically differ. This could be due to differences in how pale and bleached corals were classified in the Marshall and Baird (2000) study compared to the classification of Jokiel and Coles (1977) that was used to construct the model.

It is important to note that differences in bleaching response that we have attributed to species could also arise from differences in the depths at which the species are found, similar to what has been shown for Montastraea annularis (Baker and Weber, 1975). By way of illustration, consider two corals that have an identical bleaching response $\left(T_{\mathrm{lo}}, T_{\mathrm{hi}}\right.$ and $C_{\mathrm{sp}}$ ), with one found in shallow water whilst the other is found only in deeper water. The shallower coral will be exposed to a larger range of temperatures and increased light stress and will therefore be at an increased risk to bleaching than the deeper coral. While we do not explicitly include depth in the model, it appears that the deeper coral will
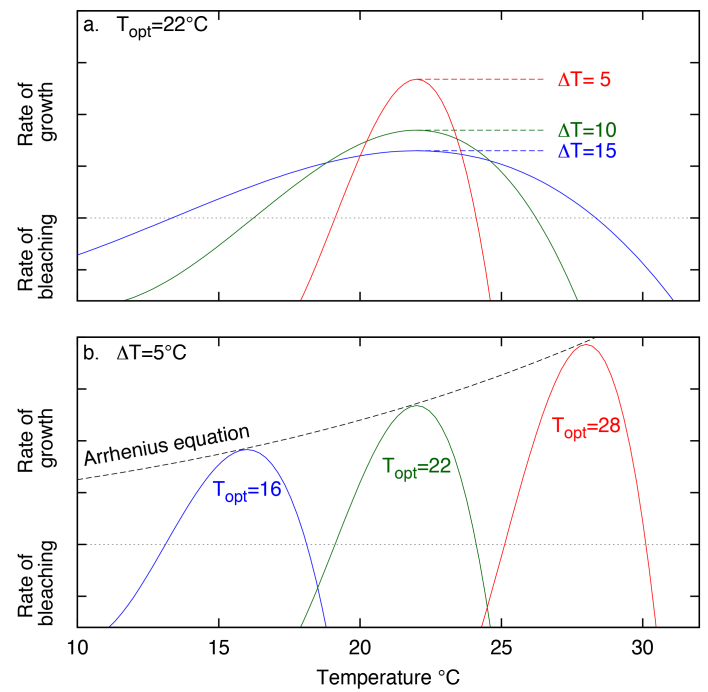

Figure 5. Illustration of the temperature dependence of biological processes in the model. Panel (a) shows the effect of changing the temperature range $\Delta T$ while holding $T_{\text {opt }}$ fixed. Panel (b) shows the effect of changing $T_{\mathrm{opt}}$ whilst holding $\Delta T$ fixed.

be more tolerant to bleaching (e.g. Berkelmans and Oliver, 1999). The extent to which depth and other environmental variables act as confounders and how their effects may be aliased into model parameters such as $C_{\mathrm{sp}}$ will be pursued in future work.

\subsubsection{The thermal envelope $(\beta)$ and average calcification rate $\left(g_{\mathrm{c}}\right)$}

There are two remaining terms to be discussed: the thermal envelope, $\beta$, from Eq. (3) and the calcification constant, $g_{\mathrm{C}}$, from Eq. (1). The thermal envelope relates differences in productivity of corals between locations, while the calcification constant puts an absolute rate on calcification. In the previous sections the absolute rates of calcification were used as the adapted response curve was determined from relative changes in calcification rate. Ideally, $g_{\mathrm{C}}$ and $\beta$ would be determined separately from independent data sets that report calcification rates using comparable experimental protocols for a broad range of locations and species. It was necessary to use a single data set to determine these two parts of the model.

Determining a value for the rate of calcification is challenging, as there is wide variation in measured calcification rates between different experimental protocols. Kleypas and Langdon (2006) identified seven experimental approaches for measuring calcification rate, with spatial scales ranging from individual corals to whole reef communities, and temporal scales from hours to millennia. Here we use the large data set of calcification rates for Porites compiled by Lough and co-workers (i.e. Lough and Barnes, 1997, 2000; Poulsen et al., 2006; Lough, 2008). This data set allows the calcifica- 

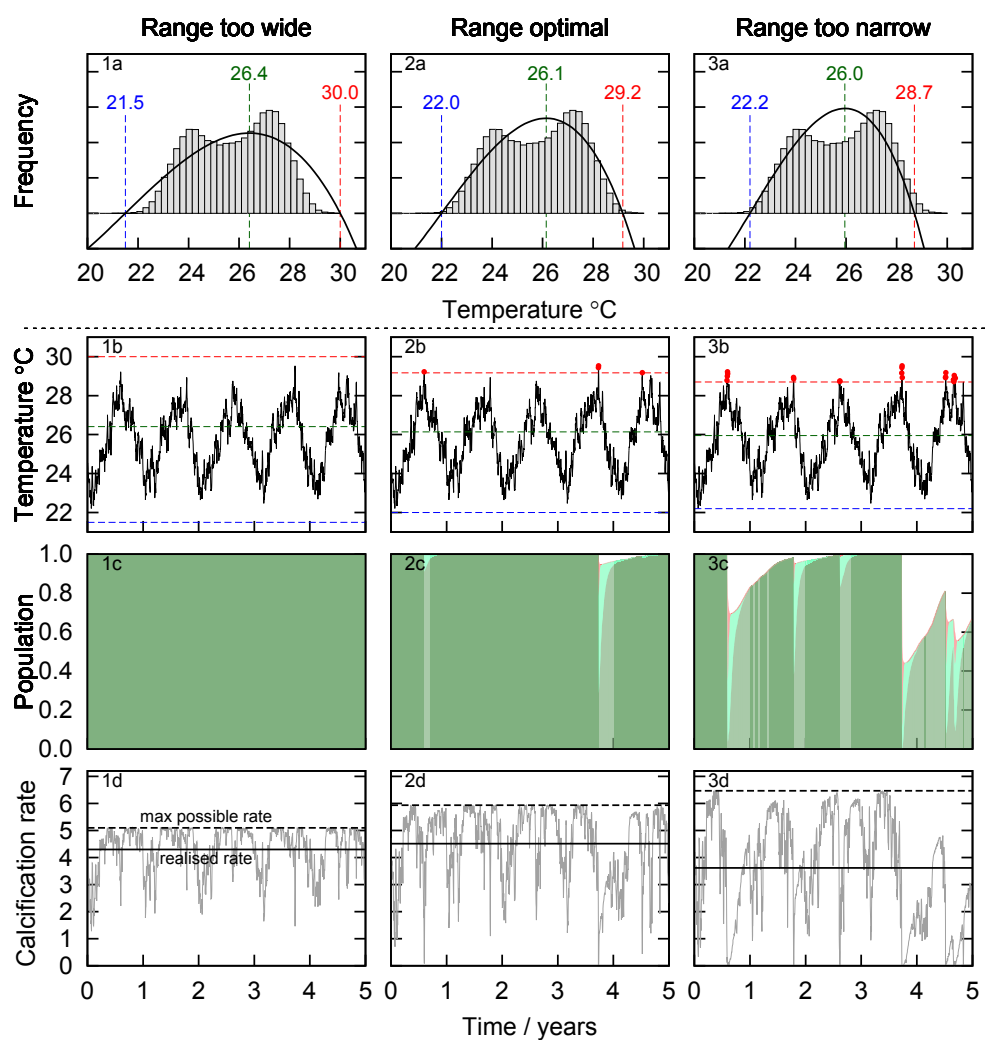

Figure 6. Illustration of how the temperature range $\left(T_{\mathrm{lo}}, T_{\mathrm{hi}}\right)$ is found by optimising the calcification rate over a historical SST record. The first row shows the histogram of historical SST with the transient temperature curve and the key temperatures $\left(T_{\mathrm{lo}}, T_{\mathrm{opt}}, T_{\mathrm{hi}}\right)$. The second row shows times series of SST together with the key temperatures. Bleaching events are marked with red dots. The third row shows the condition of the coral (colouring as in Fig. 2) and the calcification rate as a function of time, and the fourth row shows the calcification rate as a function of time.

tion rate of a single species (Porites) to be compared across 60 unique geographic locations (Shi et al., 2012; Scoffin et al., 1992; Poulsen et al., 2006; Lough, 2008; Fabricius et al., 2011; Edinger et al., 2000; Cooper et al., 2012).

The thermal envelope is characterised by examining how the rate of calcification varies between locations due to differences in local temperatures. The increase in biological function with average temperature is a well-known phenomenon and is commonly modelled using the BoltzmannArrhenius curve. This can be viewed as an upper bound on the thermal efficiency of corals, with the details of how this energy is used by a specific coral being determined by the adapted response $\alpha$ and the species constant $C_{\mathrm{sp}}$. To this point we have ignored the contribution to the temperature from the thermal envelope by implicitly setting $\beta=1$. By defining the thermal envelope as 1 when the average temperature is $27^{\circ} \mathrm{C}\left(300^{\circ} \mathrm{K}\right)$, we can extended the model, which so far has only been applied to Hawaii and the GBR, to other locations. This is achieved by defining the thermal envelope as

$\beta\left(T_{\mathrm{opt}}, E_{\mathrm{a}}\right)=\exp \left[\frac{E_{\mathrm{a}}}{R}\left(\frac{1}{300}-\frac{1}{T_{\mathrm{opt}}}\right)\right]$, where $E_{\mathrm{a}}$ is the activation energy and $R$ is the gas constant. Figure $5 \mathrm{~b}$ shows the effect of changing the average temperature $T_{\text {opt }}$ whilst the temperature range $\Delta T$ is held constant.

The calcification constant $\left(g_{\mathrm{C}}\right)$ in Eq. (9) and the activation energy $E_{\mathrm{a}}$ in Eq. (8) are found by fitting the model to the observed calcification rates. For each location the adapted temperature range was determined by maximising the calcification rate over the historical period (1900-1970). The relative distributions of aragonite saturation state were estimated from GLODAP (Key et al., 2004) and WOA (Stephens et al., 2002). Given that the changes in aragonite saturation state over the historical period are yet to be determined, we used a single (time-invariant) value of aragonite saturation state that was used in each location.

The average calcification rate over the historical period was calculated by minimising the residual between the calculated and observed calcification, shown in Fig. 8. From this the rates for the values of $g_{\mathrm{C}}=0.038 \mathrm{~g} \mathrm{~cm}^{-2} \mathrm{~d}^{-1}$ and $E_{\mathrm{a}}=60 \mathrm{~kJ} \mathrm{~mol}^{-1}$ were determined. Interestingly, the size of the calcification constant places the calcification process on the same timescale as growth and reproduction. Similarly, the 


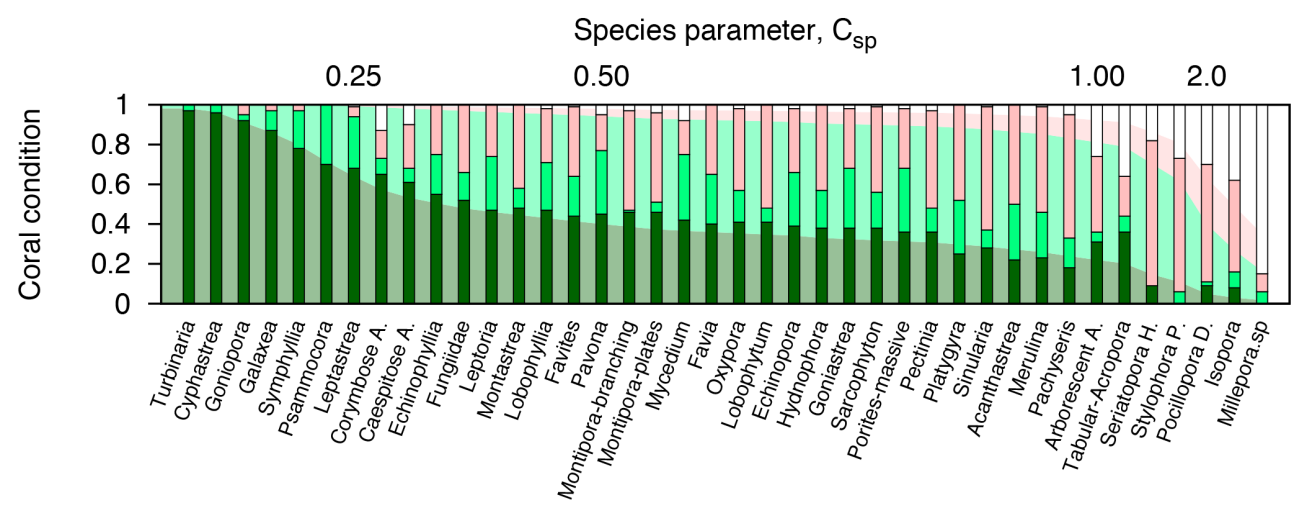

Figure 7. Comparison of the observed coral bleaching reports on the Great Barrier Reef from (Marshall and Baird, 2000) with modelled bleaching as a function of the species parameter $C_{\mathrm{sp}}$. Colour scheme as in Fig. 2.

activation energy falls within the range observed for biological processes (Dell et al., 2011).

\section{Results and assessment}

Having outlined the construction of the model, we now validate its outputs using three sets of experimental results that were not used in the construction of the model. The model was constructed starting with the smallest spatial and temporal scales (minutes, organism) and systematically built up to the largest (centuries, geographic). As no one single experiment is able to bridge these spatial and temporal timescales, we validate the model with a set of experiments, each testing different subsets of variables. In this way, although a single experiment validates only part of the model, when taken in aggregate they demonstrate the overall performance and robustness of the model.

In the final section of the results, a simplified version of the model is constructed and used to show that, within the framework of the model, the linear relationship between average sea surface temperature and calcification rate for Porites observed by Lough and Barnes (2000) arises from the interaction between the Arrhenius equation and thermal specialisation.

\subsection{Aragonite, adapted response, local climate}

The first assessment of our model compares the simulated calcification rates with those observed by Erez et al. (2011) (their Fig. 11; originally reported in Schneider and Erez, 2006). In this experiment, calcification of the coral Acropora eurystoma was measured as a function of aragonite saturation state and temperature. The comparison between the experimental results and the model output is shown in Fig. 9. This assesses the expression used for calcification (Eq. 1) and links adapted temperature response to the local climate.

The experimental data in the left-hand panel of Fig. 9 clearly displays the linear response to aragonite saturation.

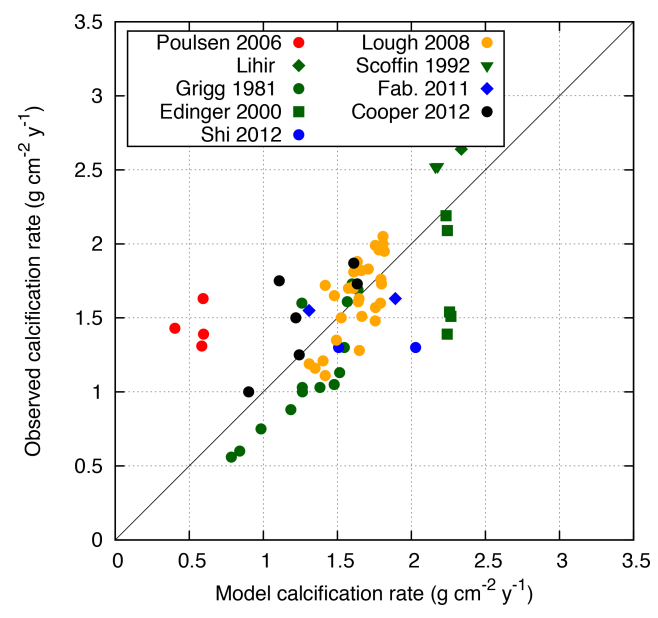

Figure 8. Comparison of observed and modelled calcification rates. The Lihir datum is the calcification rate reported for Lihir Island, Papua New Guinea, in Lough (2008).

In order to achieve a good fit with the linear response, a constant dissolution rate was added to the model so the output could be compared to the gross calcification rate measurements. The calcification rates were measured at three temperatures and show a fall in calcification rate either side of an optimum somewhere around $24^{\circ} \mathrm{C}$.

The right-hand panel of Fig. 9 plots the histogram of historical SSTs, overlaid with the adapted response curve $(\mathrm{Eq}$ 4). The high- and low-temperature thresholds that determine the adapted response curve were found using the optimisation procedure outline in Sect 2.3.2. The dashed lines that join the left- and right-hand panels of Fig. 9 demonstrate how the calcification rate depends on temperature and aragonite saturation state. 
Table 3. Translation of the states used to classify the condition of the coral in the observations of Baird and Marshall (2002) to the five states used in the model.

\begin{tabular}{ll}
\hline Model & Observation \\
\hline Normal + recovering & Normal $+1-10 \%$ \\
Pale & $11-50 \%+55-99 \%$ \\
Bleached & $100 \%$ \\
Dead & Dead \\
\hline
\end{tabular}

\subsection{Population changes, species, optimising to local climate}

This work reports the bleaching and recovery of four species of coral over the course of several months. Due to differences in bleaching assessments between experiments, it is necessary to translate the percent of coral bleached reported by Baird and Marshall to the four states that the model uses (given in Table 3).

The model was initialised with $100 \%$ healthy coral, and in situ temperatures used were for 1998 (www.aims.gov.au). Figure 10 shows good agreement between the observations and model and provides a test of the ability of the model to reproduce the observed bleaching. The values for the species constants were determined by matching the model output to the observation and are in good agreement with data from Sect. 2.3.3; this demonstrates the importance of species in modulating the extent of bleaching response and recovery.

\subsection{Population changes, optimising to local climate}

The third assessment of the model uses the reciprocal transplant experiment of Howells et al. (2013) and highlights the importance of the adapted range term. This experiment monitored the health of corals that were exchanged between reefs on the central and southern GBR. Corals relocated from the southern to the central site experienced temperatures above their adapted range and bleached due to heat stress, whilst corals transferred from the central to the southern site experienced temperature below their adapted range and bleached due to cold stress

The two locations, Nelly Bay (central GBR) and Miall Island (southern GBR), have markedly different thermal environments, which is reflected in their respective adapted ranges. Table 4 shows the thermal thresholds for the two locations calculated by four methods, using two SST time series (the NOAA AVHRR product (www.ncdc.noaa.gov/sst/) and from in situ temperature logger records). The first approach estimates the adapted range by calculating extreme percentiles of the SST distribution - in this case the percentiles correspond to 1-in-3-year temperature extremes. The second adapts a common bleaching metric (maximum monthly mean plus variance; Donner, 2011). The third employs the optimisation procedure outlined in Sect. 2.3.2 that
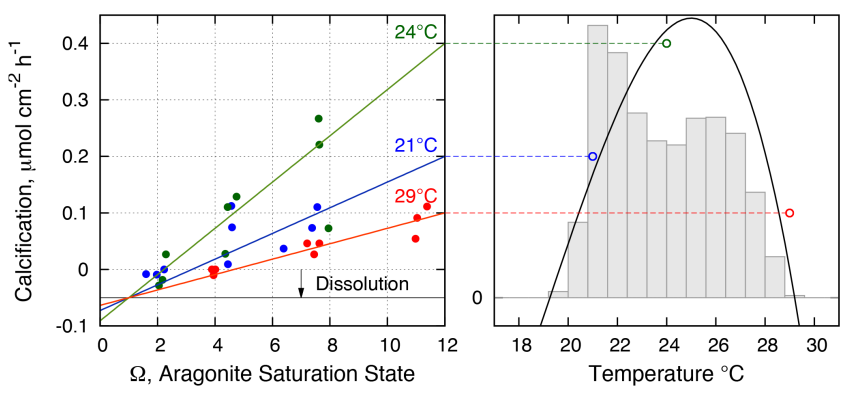

Figure 9. Left panel: calcification rate for Acropora eurystoma as a function of aragonite saturation state and temperature from Erez (2011). Right panel: histogram of daily SST for the Gulf of Aqaba from the NOAA pathfinder product (grey bars).

maximises the calcification rate over the historical period. Finally, in the empirical approach, the upper and lower thresholds were manually adjusted to reproduce the experimental observations. Table 4 shows how $T_{\mathrm{lo}}$ and $T_{\mathrm{hi}}$ depend on the temperature record (in situ vs. satellite) and the method of calculation.

There are a number of challenges when a coral's adapted range calculated from an SST product is compared to bleaching observations. Firstly, the low spatial resolution $\left(0.25^{\circ}\right.$ for NOAA - Reynolds et al., 2007; $1^{\circ}$ for HadISST - Rayner et al., 2003) means that temperature fluctuations at the scale of the reef are averaged out, so in general the thermal variability is underestimated. Secondly, hydrodynamic processes on a reef can lead to systematic differences that are not resolved by SST products and which vary throughout the year. For example, local trapping and flushing of water on a reef driven by tides and winds can result in large systematic variations in water temperatures that are not captured in the spatially averaged SST products. While in situ measurements of SSTs accurately record the reef-scale temperature, they are not widely available, often covering shorter periods, and may be subject to data integrity problems. To accurately estimate thermal thresholds, temperatures are needed over long time periods, which unfortunately rules out many in situ measurements which are in general too short and often discontinuous.

Despite the limitations in estimating the adapted range, Table 4 shows good agreement between the different approaches and the two temperature records. Despite the multitude of uncertainties, it is clear that the upper and lower thermal thresholds differ by $\sim 1.5^{\circ} \mathrm{C}$ between the central and southern GBR sites. Overall the bleaching and recovery response is well captured by the model in Fig. 11, with the qualification that the central site was strongly affected by flooding in February of 2009. Freshwater floods impact coral in a number of ways, due to low salinity stress, increased nutrient input and changes in organic matter. 
Table 4. Estimates of the adapted temperature range for the central and southern GBR sites in the reciprocal transplant experiment. The thresholds are calculated using a variety of methods and from two SST records. The empirically derived thresholds (bolded) are used in the model run shown in Fig. 11.

\begin{tabular}{|c|c|c|c|c|c|c|}
\hline & \multirow[b]{2}{*}{ Method } & & \multicolumn{2}{|c|}{ Central } & \multicolumn{2}{|c|}{ Southern } \\
\hline & & & NOAA & In situ & NOAA & In situ \\
\hline \multirow{4}{*}{$\begin{array}{l}\text { Upper } \\
\text { threshold }\end{array}$} & Percentile & 99.9th & 30.9 & 31.6 & 29.3 & 29.9 \\
\hline & Climatology & Feb $\mu+2.45 \sigma$ & 31.2 & 32.7 & 30.2 & 29.5 \\
\hline & Optimised & $T_{\mathrm{hi}}$ & 31.6 & & 30.3 & \\
\hline & Empirical & $T_{\mathrm{hi}}$ & & 31.8 & & 30.3 \\
\hline \multirow{4}{*}{$\begin{array}{l}\text { Lower } \\
\text { threshold }\end{array}$} & Percentile & 0.1 th & 20.3 & 19.4 & 18.6 & 18.5 \\
\hline & Climatology & Jul $\mu-2.45 \sigma$ & 20.2 & 19.3 & 18.5 & 18.0 \\
\hline & Optimised & $T_{\mathrm{lo}}$ & 19.7 & & 18.0 & \\
\hline & Empirical & $T_{\mathrm{lo}}$ & & 20.0 & & 18.2 \\
\hline
\end{tabular}

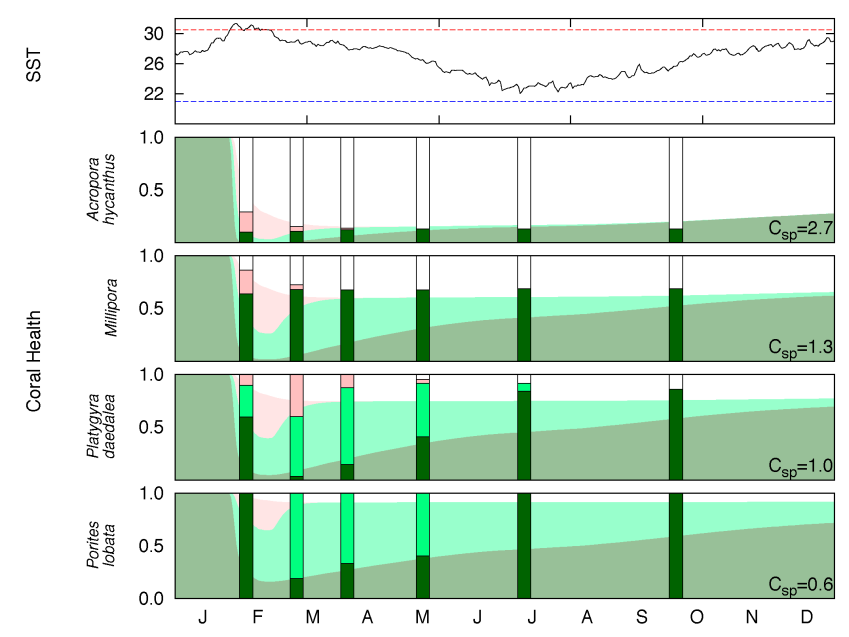

Figure 10. Comparison of model simulated beaching with that observed by Baird and Marshall (2002) on the Great Barrier Reef in 1998. Colour scheme as in Fig. 2.

\subsection{Interpreting the Porites calcification vs. SST relationship}

One of the most firmly established relationships that describes the growth rates of coral is the correlation between average SST and average calcification rate (Lough and Barnes, 2000; Lough 2008). This linear relationship, hereafter referred to as $L \& B$, has some surprising features. The L\&B relationship predicts the rate of calcification falls to zero when the average SST is $\sim 22^{\circ} \mathrm{C}$ and when annual minimum SST is $\sim 17.5^{\circ} \mathrm{C}$. This linear dependence on temperature is difficult to reconcile with thermal response curves observed for coral (i.e. adapted response) or to a more general biological temperature relationship like the Arrhenius curve. This suggests that the L\&B may arise from the interaction of several processes.

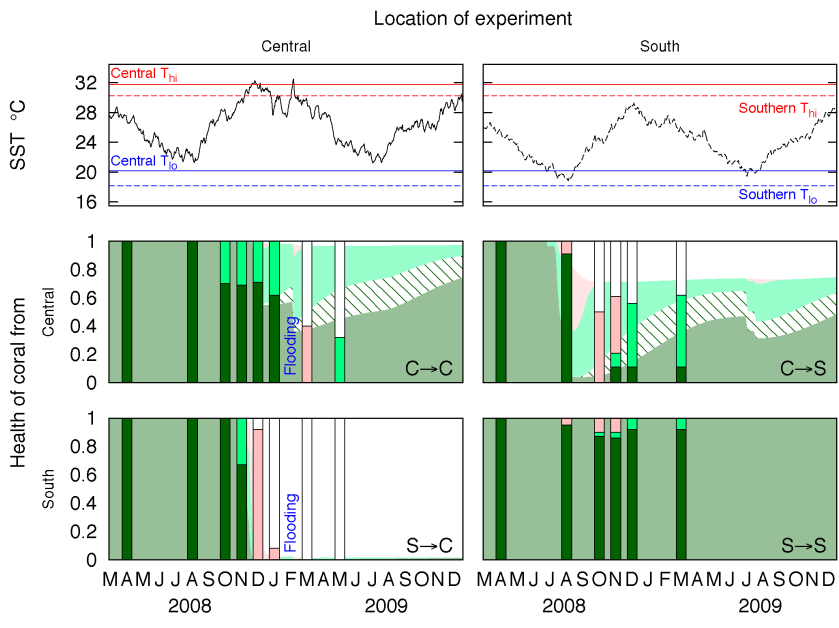

Figure 11. Comparison of model runs with the reciprocal coral transplant experiment (Howells et al., 2013). Top panels show SST in the central GBR (top left) and southern GBR (top right) with the adapted ranges shown for both locations. The lower four panels show observed coral health (bars) and the model coral health (continuous fill) for the four experiments using the colour scheme of Fig. 2. The four experiments are central corals remaining in central GBR (centre left), central corals transplanted to southern GBR (centre right), southern corals transplanted to central GBR (bottom left) and southern corals remaining in southern GBR (bottom right).

In this section we demonstrate how a simplified version of the model can help understand the $L \& B$ relationship in terms of thermal adaptation. To derive a simplified model (SM), a number of approximations are made to the equation for calcification rate from Eq. (1), which leaves only the Arrhenius and thermal specialisation terms. The resulting expression for calcification rate depends only on the adapted temperature range $\left[T_{\mathrm{lo}}, T_{\mathrm{hi}}\right]$. Additionally the healthy population $P_{\mathrm{H}}$, the species constant $C_{\mathrm{sp}}$, the aragonite saturation state $\Omega$, and the daily insolation are all set to be constant. This is equivalent to replacing these variables by their long-term averages. 
The next step is to take a long-term average of the adapted response curve in Eq. (3). First, the adapted range for each location is set to the 1 st and 99th percentiles of the temperature distribution rather than optimising the calcification rate as outlined in Sect. 3.2. Second, the thermal specialisation term in Eq. (4) is approximated as $4 \Delta T^{-4-\delta}$. Finally, it is assumed that at each location the chance of temperature being between $T_{\mathrm{lo}}$ and $T_{\mathrm{hi}}$ is equally likely - i.e. the climatology of the temperatures is rectangular. This allows the average over time to be calculated, with the result that $\alpha$ can be replaced by $\Delta T^{1-\delta}$ in Eq. (3).

The final result is that the calcification rate in the SM can be approximated as

$\dot{G}_{\text {ave }}=A \exp \left[\frac{E_{\mathrm{a}}}{R}\left(\frac{1}{300}-\frac{1}{T_{\text {ave }}}\right)\right] \frac{1}{\Delta T^{1-\delta}}$,

where $\Delta T=T_{99}-T_{01} ; E_{\mathrm{a}}$ is the activation energy; $\delta$ is the normalisation factor that rewards thermal specialisation; and $A$ is a constant which absorbs details such as aragonite saturation state, species and average level of bleaching. Eq. (10) has a very simple interpretation; the calcification rate is given by an Arrhenius curve that depends on the average temperature and is modulated by the temperature range.

The fit of the SM (Eq. 10) to the data of L\&B is shown in Fig. 12b. This is the same calcification rate data used in Fig. 8 for a single species (Porites) across 60 unique geographic locations (Shi et al., 2012; Scoffin et al., 1992; Poulsen et al., 2006; Lough, 2008; Fabricius et al., 2011; Edinger et al., 2000; Cooper et al., 2012). The goodness of fit can be gauged by comparing the data points, which are coloured by their temperature range to the family of Arrhenius curves obtained by setting to $3,4,6,8$ and $15^{\circ} \mathrm{C}$. The values of the three parameters were determined to be $A=1.8, E_{\mathrm{a}}=50 \mathrm{kJmol}^{-1}$ and $\delta=0$. The values of the activation energy in the simplified and full versions of the model are close (60 vs. 50) and the value of $\delta$ is reduced ( 0.0 vs. 0.33 ).

A decrease in the thermal specialisation is expected. The approximations used to derive the SM are more accurate near the tropics. The assumptions of a flat climatology and constant insolation are robust at the Equator but will result in an overestimation of calcification rate for more temperate locations. This overestimation results in an increase in the cost of reducing thermal adaption.

The SM also gives an insight into deviation from linearity in the L\&B data. The family of Arrhenius curves in Fig. 12b maps out a large area of possible calcification rates. By considering how the average temperature and temperature range co-vary with reef location, a region of likely calcification rates arises. Figure 12a shows the average and range of SST from the $0.25^{\circ}$ NOAA SST (Reynolds et al., 2007) for each location in the L\&B data set. Most of the average-range data in Fig. 12a falls into a typical-temperature area (shaded grey) that is defined by fitting three SST average-range relationships. When the average-range relationships are substituted into Eq. (10), the typical-temperature area from Fig. 12a is flipped and distorted into the typical-calcification area in Fig. 12b. The final step to link the SM to the L\&B relationship is to fit a regression line through the typical-calcification area. As the L\&B relationship neatly bisects the typicalcalcification area, the lines are very close to one another, which illustrates how the L\&B relationship emerges from two basic biological relationships. In addition, our SM also allows the spread of calcification rates about the L\&B relationship to be understood. For example the spread of points above the line around the average temperature $26^{\circ} \mathrm{C}$ can be explained by the relationship between temperature range and averages in different water masses.

Outliers from the L\&B relationship have atypical temperature ranges. For example, the calcification rate for Houtman Abrolhos Reef (Cooper et al., 2012), which is anomalously high if the L\&B relationship is used, can be understood in SM as arising from this site having a lower temperature range than is typical for the average temperature. Similarly, the Milne Bay calcification rates of Fabricius et al. (2011) lie below the L\&B relationship due to the site having a larger temperature range than expected for the average temperature.

The clear outliers from the SM are the results of Poulsen et al. (2006) from the Arabian Gulf, which stand out as the four red data points in Fig. 12b. Contrary to the observed calcification rate, Eq. (10) predicts a very low calcification rate due to the large temperature range. This large disagreement may in part be due to neglecting the aragonite saturation state, which is highest (globally) in the Arabian Gulf (Kleypas et al., 1999), or it may simply suggest that the extreme conditions have resulted in a very different biological response in these corals.

\section{Discussion}

The new model presented here can be viewed as extending and bringing together existing models of coral growth that include responses to temperature and ocean acidification (Silverman et al., 2009; Buddemeier et al., 2008) that have different foci and limitations. The approach of Buddemeier et al. (2008) consisted of a high-resolution model in time, focusing on specific locations and species, while that of Silverman et al. (2009) considered large-scale trends and takes a global view. This new model brings together the low-level detail of species-level responses and adaption to local environments that underpins the COMBO model (Buddemeier et al., 2008), and by comparing across species and locations it distills the trends and patterns that emerge on a global scale (Silverman et al., 2009).

Our model extends the work of Silverman et al. (2009), as by including high-frequency SST information and discriminating between individual species we are able to more realistically describe bleaching events. In the Silverman approach the gross calcification rate is proportional to the area of the reef and the proportion of the reef that is calcifying 


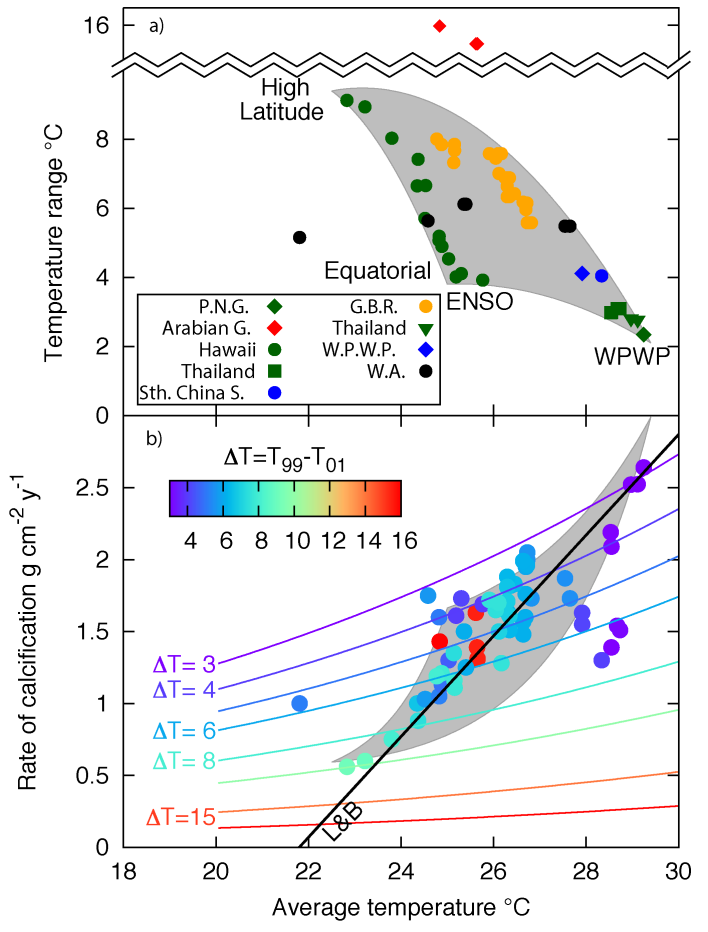

Figure 12. The upper panel shows the average and range of SST from the $0.25^{\circ} \times 0.25^{\circ}$ NOAA SST (Reynolds et al., 2007) for each coral location. The family of Arrhenius curves in the lower panel maps out a large area of possible calcification rates, while the symbol colours show the adapted range. Overlain on this plot is the linear relationship of Lough (2008).

and depends on the temperature and the aragonite saturation state. The aragonite saturation state is proportional to the inorganic precipitation rate, which includes a complex dependence on temperature. Specifically, the temperature dependence is modelled by a Gaussian curve centred on an optimal temperature, the width of which depends on the aragonite saturation state. However, relative to our model, the impact of temperature on calcification is quite simplistic; the fraction of calcifying coral is reduced by $50 \%$ if the maximum monthly SST increases by $1^{\circ} \mathrm{C}$.

The COMBO model of Buddemeier et al. (2008) also shares many similarities with the model presented here. For example, the aragonite dependence is similar to our model, in that a range of responses from flat to a linear decrease can be modelled. In COMBO the temperature dependence of calcification is also modelled as a cubic polynomial; however it needs to be parameterised for each location and potentially for each species. Our model extends Buddemeier et al. (2008) by identifying transferable relationships that avoid re-parameterisation for each new location, thereby allowing it to be applied globally.

Another important point of difference is in how this temperature response impacts the coral. In the COMBO model bleaching is modelled by relating degree heating weeks
(DHW) to a percentage of coral mortality (see Fig. 3 of Hoeke et al., 2011). For a moderate increase in complexity, our new model moves beyond the two (binary) coral health states offered by DHW (healthy or bleached) to four states (healthy, pale, bleached, dead) which are used to link growth and stress processes within coral populations. In doing this the thermal thresholds emerge naturally as a consequence of the trade-off between growth and stress, replacing the statistic heuristics such as mean monthly maximum that are used in the DHW calculation. It also moves away from the need to rely on a fixed recovery period (e.g. Donner et al., 2005) by explicitly modelling the recovery process as its dependence on temperature.

In this work the temperature response is key to understanding how corals grow and bleach due to temperature stress. The adapted response function that captures this temperature dependence is an example of a reaction norm - a response of an organism that varies continuously with an environmental variable (Stearns, 1998). Reaction norms describe how organisms with the same genetics (genotype) are able to express a variety of responses depending on its environment (phenotype). Connections between multiple traits can be made by realising that the adapted response is a reaction norm. All of the traits in the model share a common temperature dependence reflecting their dependence on the energy supplied by symbiosis, and the differences between species of coral (i.e. genotype differences) manifest as traits that are either up-regulated or down-regulated in a correlated fashion by the species parameter $\left(C_{\mathrm{sp}}\right)$.

The way we modelled thermal specialisation in terms of a reaction norm (Eq. 8) has been used by researchers to investigate the trade-offs made by thermal generalists and specialists (e.g. Gilchrist, 1995). The correlated up- and downregulation of growth and thermal protection processes that is controlled by the species parameter $C_{\mathrm{sp}}$ can also be viewed in terms of resource allocation. This trade-off is analogous to the $\kappa$ rule in dynamic energy budget theory that determines the allocation of energy between growth and reproduction (Nisbet et al., 2000). The extremes of this trade-off spectrum correspond to two distinct strategies for coping with thermal stress: a growth and a resilience strategy. Small values of the species parameter correspond to slow-growing species that can survive bleaching episodes, whilst large values correspond to fast-growing species that can regrow quickly from a disturbance. The relative merits of these two thermal resilience strategies under global warming scenarios remain unclear and active areas of current research.

There are number of areas in which the model presented here could be improved, and these could serve as a starting point for future research. Rather than using insolation, the ambient light levels could be explicitly calculated using a radiation transfer model (RTM), which subsequently would be passed to a detailed photobiology model in order to quantitatively represent net photosynthesis. An RTM needs parameters for a range of processes (e.g. cloud levels, dis- 
solved organic matter, bathymetry) in order to calculate the losses as light passes through the atmosphere and water column. Unfortunately, this would be very challenging to implement as many of the parameters are not known or measured in many coral reef environments. In principle, some of these unknowns could be determined from remote sensing but at present are beyond the scope of this work (see HoeghGuldberg et al., 2007).

Realistic models of photobiology involve a large number of tightly coupled processes whose parameterisation depends on the species and the environmental history of the coral (see Gustafsson et al., 2013). The model can be extended to include more biological processes, in greater detail, and the general relationships found in this work can serve as overarching constraints on the more detailed one. For example, a more detailed model might explicitly include energy reserves and have a range of mechanisms to mitigate thermal stress, which, when coupled together, result in a trade-off between bleaching sensitivity and growth rate similar to the one described in this paper.

The model relies heavily on temperature time series, which are subject to a number of uncertainties. When in situ temperatures were unavailable we used the NOAA SST product, which has a resolution of $0.25^{\circ} \times 0.25^{\circ}$. However, measured calcification rates of the coral skeleton are a proxy record of local temperatures on a much finer spatial resolution. There are often large differences between in situ recorded temperature and the SST products, particularly in the coastal environment (Lima and Wethey, 2012). This difference may account for some of the differences between the model and observations. For example, many sites for which the model underestimates the calcification rate (e.g. Poulsen et al., 2006) are close to land and therefore may be influenced by local warming that increases the local temperature range.

In this study we simulate the calcification rate response of reef-building corals to models of ocean warming and acidification. At present, a component of our modelled calcification rate is driven by bulk water aragonite saturation state $\Omega_{\text {arg }}$, which is a function of $\left[\mathrm{CO}_{3}^{2-}\right]$. Given the experimental responses observed to date (Fig. 1), this assumption remains an important component of our understanding of the drivers of coral calcification. Additional drivers that are also important to the modelled output include light intensity, adapted temperature ranges and energy availability. Given the current concerns of ocean acidification threats for coral reef processes, future efforts in the evolution of this model will seek to incorporate other potentially more important drivers of calcification, including $P_{\text {net }}$ (e.g. Jokiel et al., 2014). in order to fully understand the risk and influence that future decreases in $\Omega_{\text {arg }}$ pose for calcification processes of reefbuilding corals. While the response of the coral reef may be inferred from this response, as it is likely correlated to the performance of individuals within the population, we do not explicitly simulate community coral reef calcification dynamics. Clearly the response of the entire coral reef to warm- ing and ocean acidification is more complex, and capturing this requires inclusion of additionally important species such as crustose coralline algae (CCA), which are more sensitive to OA condition than other reef-building corals (Kuffner et al., 2008) and different dissolution processes, such as bioerosion and mechanical damage (Silverman et al., 2009; Andersson and Gledhill, 2013). Consequently, dissolution processes have not been included in our model and coral reefs will not dissolve until $\Omega<1$, while in reality net coral loss will likely occur much sooner (i.e. for values of $\Omega>1$ ).

It is clear from the wide range of temperature regimes in which corals live that they are able to adapt to local conditions, but the rate at which this adaptation takes place is not known. See Coles and Brown (2003) for review of the possible routes of adaption. The fastest of which are phenotypic processes that operate on monthly to yearly timescales, and include enzymatic and physiological responses and shuffling or exchange of zooxanthellae (including the adaptive bleaching hypothesis; Buddemeier and Fautin, 1993; Kinzie et al., 2001). On longer timescales from decades to centuries, genetic changes are effected by selection pressure and evolution. The underlying mechanisms, the range or plasticity of this change, and the rate of these adaption processes are as yet not fully understood and remains an ongoing area of research. Adaption on annual to decadal timescales is of greatest relevance to medium-term climate projections of coral health. In our model we do not explicitly consider adaptation, and we note that in applying this model, particularly over longer periods, the potential for adaptation needs to be considered.

Coral bleaching and ocean acidification have been identified as two of the key stressors on coral. However, corals face many additional pressures, such as changes in nutrient supply and light, riverine input, storm damage, disease and human pressures (Burke et al., 2011). All of these can impact on coral calcification rates and reduce the ability of a coral to buffer the impacts of increasing temperatures and thereby reduce its resilience to environmental stress (Edinger et al., 2000). As many of these stressors are stochastic in nature it is impossible to explicitly model these mechanisms and hence the response of corals. However this model provides a solid foundation that allows us to explore how these processes may impact corals and how these pressures may interact with ocean acidification and increasing ocean temperatures.

\section{Conclusions}

Corals reefs are diverse ecosystems that support about $25 \%$ of global biodiversity. Rising $\mathrm{CO}_{2}$ levels in the atmosphere and the ocean are driving observed increases in SST and ocean acidification. While these are not the only pressures corals are facing, they do represent two key stressors. In order to predict the future viability of coral reefs, it is essential 
to understand the factors that impact the health of corals and their calcification rates.

Here we present a new model that uses temperature and carbonate chemistry to describe coral health and calcification rate. By synthesising published observational studies we link rates of growth, recovery and calcification to rates of bleaching and temperature-stress-induced mortality, which enables changes in coral health and population to be explicitly modelled. Our work highlights the importance of temperature range, not just the upper threshold.

This new model draws on observations of corals from different locations and from different taxa to identify general, transferable relationships that link rates of growth, bleaching and calcification. The model is underpinned by four key principles: the Arrhenius equation, thermal specialisation, resource allocation trade-offs, and adaption to local environment. These general relationships allow the model to be constructed from a range of experimental and observational data and to minimise the number of "free parameters", which avoids re-parameterisation for each new location, thereby allowing it to be applied globally. The model was assessed against independent data and is shown to capture the observed response of individual corals. It was demonstrated how the linear relationship between average SST and calcification rate can be viewed as a consequence of thermal specialisation.
We show, by simplifying our model, that the observed linear response in global calcification rates reported by Lough and Barnes (2000) can be understood in terms of thermal specialisation. The results suggest that, despite the implicit complexity of the coral reef environment, a simple model based on temperature, carbonate chemistry and different species can be useful for understanding how corals respond to stress. Finally, our work highlights the importance of unifying the responses to increased temperature and ocean acidification, and the importance of long-term in situ measurements of temperature, carbonate chemistry and coral health. 


\section{Appendix A}

Table A1. Appendix of terms used in the model.

\begin{tabular}{|c|c|c|c|}
\hline & Name & Variable/equation & Value/source \\
\hline \multirow[t]{5}{*}{ Light } & Date in years & $y$ & \\
\hline & Latitude in radians & $\phi$ & ReefBase (http//:www.reefbase.org) \\
\hline & Declination of sun & $d=-23.44^{\circ} \cos \left(y+\frac{10}{365}\right)$ & \\
\hline & Relative location of the subsolar point & $h_{0}=\left\{\begin{array}{c}\pi \text { if } \tan \phi \tan d>+1 \\
0 \text { if } \tan \phi \tan d<-1 \\
\arccos (-\tan \phi \tan d) \text { otherwise }\end{array}\right.$ & \\
\hline & Daily average insolation & $\bar{Q}^{\text {day }}=\frac{0.5}{\pi}\left(h_{0} \sin \phi \sin \delta+\cos \phi \cos \delta \sinh _{0}\right)$ & $0.27-0.73$ \\
\hline \multirow[t]{4}{*}{ Calcification } & Aragonite saturation state & $\Omega$ & Reconstruction \\
\hline & Degree of curvature & $\kappa$ & $0-5$ \\
\hline & Cross-over point & ( & 2.8 \\
\hline & Response to aragonite saturation state & $\gamma\left(\Omega ; \Omega_{\mathrm{C}}, \kappa\right)=\frac{\Omega-1+0.1 \kappa}{1+\kappa(\Omega-1+0.1 \kappa)} \frac{1+\kappa\left(\Omega_{\mathrm{c}}-1+0.1 \kappa\right)}{\Omega_{\mathrm{c}}-1+0.1 \kappa} \frac{\Omega_{\mathrm{c}}-1}{3.5-1}$ & $0-1.5$ (approx.) \\
\hline \multirow[t]{8}{*}{ Temperature } & Sea surface temperature & $T$ & Satellite data \\
\hline & Lower threshold & $T_{\mathrm{lo}}$ & Determined \\
\hline & Upper threshold & $T_{\mathrm{hi}}$ & Determined \\
\hline & Temperature range & $\Delta T$ & Determined \\
\hline & Optimal temperature & $T_{\mathrm{lo}}+\frac{1}{\sqrt{3}} \Delta T$ & Determined \\
\hline & Thermal specialisation & $\operatorname{spec}(\Delta T)=4 \times 10^{-4} \exp [-0.33(\Delta T-10)]$ & \\
\hline & Adapted temperature response & $\alpha\left(T ; T_{\mathrm{opt}}, \Delta T\right)=\left\{T>T_{\mathrm{lo}}:-\left(T-T_{\mathrm{lo}}\right)\left(\left(T-T_{\mathrm{lo}}\right)^{2}-\Delta T^{2}\right) \cdot \operatorname{spec}(\Delta T)\right.$ & \\
\hline & Thermal envelope & $\beta\left(T_{\mathrm{opt}}, E_{\mathrm{a}}\right)=\exp \left[\frac{E_{\mathrm{a}}}{R}\left(\frac{1}{300}-\frac{1}{T_{\mathrm{opt}}}\right)\right]$ & \\
\hline \multirow[t]{8}{*}{ Population } & Proportion healthy & $P_{\mathrm{H}}$ & $0-1$ \\
\hline & Proportion recovering & $P_{\mathrm{R}}$ & $0-1$ \\
\hline & Proportion pale & $P_{\mathrm{P}}$ & $0-1$ \\
\hline & Proportion bleached & $P_{\mathrm{B}}$ & $0-1$ \\
\hline & Bleaching rate constant & $r_{\mathrm{B}}$ & $8.0 d^{-1}$ \\
\hline & Recovery rate constant & $r_{\mathrm{R}}$ & $0.2 d^{-1}$ \\
\hline & Growth rate constant & $r_{\mathrm{G}}$ & $0.02 d^{-1}$ \\
\hline & Mortality rate constant & $r_{\mathrm{M}}$ & $0.04 d^{-1}$ \\
\hline
\end{tabular}


Acknowledgements. This research was conducted with the support of the Pacific-Australia Climate Change Science and Adaptation Planning Program funded by AusAID in collaboration with the Department of Climate Change and Energy Efficiency, and delivered by the Bureau of Meteorology and the Commonwealth Scientific and Industrial Research Organisation (CSIRO). We also are grateful to Paul Jokiel, Sönke Hohn, Jack Middelburg and one anonymous reviewer for their constructive comments throughout the review process.

Edited by: J. Middelburg

\section{References}

Adjeroud, M., Michonneau, F., Edmunds, P. J., Chancerelle, Y., Loma, T. L., Penin, L., Thibaut, L., Vidal-Dupiol, J., Salvat, B., and Galzin, R.: Recurrent disturbances, recovery trajectories, and resilience of coral assemblages on a South Central Pacific reef, Coral Reefs, 28, 775-780, doi:10.1007/s00338-009-05157, 2009.

Albright, R., Mason, B., and Langdon, C.: Effect of aragonite saturation state on settlement and post-settlement growth of Porites astreoides larvae, Coral Reefs, 27, 485-490, doi:10.1007/s00338-008-0392-5, 2008.

Al-Horani, F. A.: Effects of changing seawater temperature on photosynthesis and calcification in the scleractinian coral Galaxea fascicularis, measured with $\mathrm{O}_{2}, \mathrm{Ca}_{2}^{+}$and $\mathrm{pH}$ microsensors, Sci. Mar., 69, 347-354, 2005.

Andersson, A. J. and Gledhill, D.: Ocean acidification and coral reefs: effects on breakdown, dissolution, and net ecosystem calcification, Annu. Rev. Mar. Sci., 5, 321-348, doi::10.1146/Annurev-Marine-121211-172241, 2013.

Andersson, A. J., Kuffner, I. B., Mackenzie, F. T., Jokiel, P. L., Rodgers, K. S., and Tan, A.: Net Loss of $\mathrm{CaCO}_{3}$ from a subtropical calcifying community due to seawater acidification: mesocosm-scale experimental evidence, Biogeosciences, 6 , 1811-1823, doi:10.5194/bg-6-1811-2009, 2009.

Anthony, K. R. N. and Hoegh-Guldberg, O.: Variation in coral photosynthesis, respiration and growth characteristics in contrasting light microhabitats: an analogue to plants in forest gaps and understoreys?, Funct. Ecol., 17, 246-259, 2003a.

Anthony, K. R. N. and Hoegh-Guldberg, O.: Kinetics of photoacclimation in corals, Oecologia, 134, 23-31, 2003b.

Anthony, K. R. N., Hoogenboom, M. O., Maynard, J. A., Grottoli, A. G., and Middlebrook, R.: Energetics approach to predicting mortality risk from environmental stress: a case study of coral bleaching, Funct. Ecol., 23, 539-550, doi:10.1111/j.13652435.2008.01531.x, 2009.

Baird, A. H. and Marshall, P. A.: Mortality, growth and reproduction in scleractinian corals following bleaching on the Great Barrier Reef, Mar. Ecol.-Prog. Ser., 237, 133-141, doi:10.3354/Meps237133, 2002.

Baird, A. H., Bhagooli, R., Ralph, P. J., and Takahashi, S.: Coral bleaching: the role of the host, Trends Ecol. Evol., 24, 16-20, doi:10.1016/j.tree.2008.09.005, 2009.

Baker, A. C., Glynn, P. W., and Riegl, B.: Climate change and coral reef bleaching: An ecological assessment of long-term impacts, recovery trends and future outlook, Estuarine, Coastal and Shelf Science, 80, 435-471, doi:10.1016/j.ecss.2008.09.003, 2008.

Baker, P. A. and Weber, J. N.: Coral growth rate: variation with depth, Phys. Earth Planet. In., 10, 135-139, 1975.

Berkelmans, R. and Oliver, J. K.: Large-scale bleaching of corals on the Great Barrier Reef, Coral Reefs 18, 55-60, 1999.

Berkelmans, R., De'ath, G., Kininmonth, S., and Skirving, W. J.: A comparison of the 1998 and 2002 coral bleaching events on the Great Barrier Reef: spatial correlation, patterns, and predictions, Coral Reefs, 23, 74-83, doi:10.1007/s00338-003-0353-y, 2004.

Broecker, W. S., Langdon, C., Takahashi, T., and Peng, T.H.: Factors controlling the rate of $\mathrm{CaCO}_{3}$ precipitation on Great Bahama Bank, Global Biogeochem. Cy., 15, 589-596, doi::10.1029/2000gb001350, 2001.

Brown, B. E. and Suharsono: Damage and recovery of coral reefs affected by El-Niño related seawater warming in the Thousand Islands, Indonesia, Coral Reefs, 8, 163-170, doi:10.1007/Bf00265007, 1990.

Brown, J. H., Gillooly, J. F., Allen, A. P., Savage, V. M., and West, G. B.: Toward a metabolic theory of ecology, Ecology, 85, 17111789, 2004.

Buddemeier, R. W. and Fautin, D. G.: Coral bleaching as an adaptive mechanism, BioScience 43, 320-326, 1993.

Buddemeier, R. W., Jokiel, P. L., Zimmerman, K. M., Lane, D. R., Carey, J. M., Bohling, G. C., and Martinich, J. A.: A modeling tool to evaluate regional coral reef responses to changes in climate and ocean chemistry, Limnol. Oceanogr.-Methods, 6, 395411, 2008.

Burke, L., Reytar, K., Spalding, M., and Perry, A.: Reefs at risk revisited, World Resources Institute, Washington, DC, USA, 130 pp., 2011.

Cantin, N. E. and Lough, J. M. Surviving coral bleaching events: Porites growth anomalies on the Great Barrier Reef, PLoS ONE, 9, e88720, doi:10.1371/journal.pone.0088720, 2014.

Cantin, N. E., Cohen, A. L., Karnauskas, K. B., Tarrant, A. M., and McCorkle, D. C.: Ocean warming slows coral growth in the central Red Sea, Science, 329, 322-325, doi:10.1126/science.1190182, 2010.

Carilli, J. E., Norris, R. D., Black, B. A., Walsh, S. M., and McField, M.: Local stressors reduce coral resilience to bleaching, PLoS ONE, 4, e6324, doi:10.1371/journal.pone.0006324, 2009.

Ceccarelli, D. M., Richards, Z. T., Pratchett, M. S., and Cvitanovic, C.: Rapid increase in coral cover on an isolated coral reef, the Ashmore Reef National Nature Reserve, northwestern Australia, Mar. Freshwater Res., 62, 1214-1220, doi:10.1071/mf11013, 2011.

Chalker, B., Dunlap, W., and Oliver, J.: Bathymetric adaptations of reef-building corals at Davies Reef, Great Barrier Reef, Australia. II. Light saturation curves for photosynthesis and respiration, J. Exp. Mar. Biol. Ecol., 73, 37-56, 1983.

Chan, N. C. S. and Connolly, S. R.: Sensitivity of coral calcification to ocean acidification: a meta-analysis, Glob. Change Biol., 19, 282-290, doi:10.1111/Gcb.12011, 2013.

Coles, S. L. and Brown, B. E.: Coral bleaching - Capacity for acclimatization and adaptation, Adv. Mar. Biol., 46, 183-223, doi:10.1016/S0065-2881(03)46004-5, 2003.

Coles, S. L. and Brown, E. K.: Twenty-five years of change in coral coverage on a hurricane impacted reef in Hawai ' $i$ : the importance 
of recruitment, Coral Reefs, 26, 705-717, doi:10.1007/s00338007-0257-3, 2007.

Cooper, T. F., De'ath, G., Fabricius, K. E., and Lough, J. M.: Declining coral calcification in massive Porites in two nearshore regions of the northern Great Barrier Reef, Glob. Change Biol. 14, 529-538, doi:10.1111/j.1365-2486.2007.01520.x, 2008.

Cooper, T. F., O'Leary, R. A., and Lough, J. M.: Growth of Western Australian corals in the anthropocene, Science, 335, 593-596, doi:10.1126/science.1214570, 2012.

Dell, A. I., Pawar, S., and Savage, V. M.: Systematic variation in the temperature dependence of physiological and ecological traits, P. Natl. Acad. Sci. USA, 108, 10591-10596, doi:10.1073/pnas.1015178108, 2011.

de Putron, S. J., McCorkle, D. C., Cohen, A. L., and Dillon, A. B.: The impact of seawater saturation state and bicarbonate ion concentration on calcification by new recruits of two Atlantic corals, Coral Reefs, 30, 321-328, doi:10.1007/S00338010-0697-Z, 2011.

Diaz-Pulido, G., McCook, L. J., Dove, S., Berkelmans, R., Roff, G., Kline, D. I., Weeks, S., Evans, R. D., Williamson, D. H., and Hoegh-Guldberg, O.: Doom and boom on a resilient reef: climate change, algal overgrowth and coral recovery, PLoS One, 4, e5239, doi:10.1371/journal.pone.0005239, 2009.

Doney, S. C., Fabry, V. J., Feely, R. A., and Kleypas, J. A.: Ocean acidification: the other $\mathrm{CO}_{2}$ problem, Annu. Rev. Mar. Sci., 1, 169-192, doi:10.1146/annurev.marine.010908.163834, 2009.

Donner, S. D.: Coping with commitment: Projected thermal stress on coral reefs under different future scenarios, PLos ONE, 4, e5712, doi:10.1371/journal.pone.0005712, 2009.

Donner, S. D.: An evaluation of the effect of recent temperature variability on the prediction of coral bleaching events, Ecol. Appl., 21, 1718-1730, 2011.

Donner, S. D., Skirving, W. J., Little, C. M., Oppenheimer, M., and Hoegh-Guldberg, O. V. E.: Global assessment of coral bleaching and required rates of adaptation under climate change, Glob. Change Biol., 11, 2251-2265, doi:10.1111/j.13652486.2005.01073.x, 2005.

Dubinsky, Z., Falkowski, P., Porter, J., and Muscatine, L.: Absorption and utilization of radiant energy by light-and shade-adapted colonies of the hermatypic coral Stylophora pistillata, P. Roy. Soc. Lond. B Bio., 222, 203-214, 1984.

Edinger, E. N., Limmon, G. V., Jompa, J., Widjatmoko, W., Heikoop, J. M., and Risk, M. J.: Normal coral growth rates on dying reefs: Are coral growth rates good indicators of reef health?, Mar. Pollut. Bull., 40, 404-425, doi:10.1016/S0025326x(99)00237-4, 2000.

Edmunds, P. J.: The effect of sub-lethal increases in temperature on the growth and population trajectories of three scleractinian corals on the southern Great Barrier Reef, Oecologia, 146, 350364, doi:10.1007/s00442-005-0210-5, 2005.

Edmunds, P. J.: Differential effects of high temperature on the respiration of juvenile Caribbean Corals, Bull. Mar. Sci., 83, 453-464, 2008.

Erez, J., Reynaud, S., Silverman, J., Schneider, K., and Allemand, D.: Coral calcification under ocean acidification and global change, Coral Reefs, 151-176, doi:10.1007/978-94-007-01144_10, 2011.

Fabricius, K. E., Langdon, C., Uthicke, S., Humphrey, C., Noonan, S., De'ath, G., Okazaki, R., Muehllehner, N., Glas, M. S., and
Lough, J. M.: Losers and winners in coral reefs acclimatized to elevated carbon dioxide concentrations, Nature Climate Change, 1, 165-169, doi:20.1038/nclimate1122, 2011.

Frieler, K., Meinshausen, M., Golly, A., Mengel, M., Lebek, K., Donner, S. D., and Hoegh-Guldberg, O.: Limiting global warming to 2 degrees Celsius is unlikely to save most coral reefs, Nature Climate Change, 3, 165-170, doi:10.1038/nclimate1674, 2013.

Gattuso, J. P., Frankignoulle, M., Bourge, I., Romaine, S., and Buddemeier, R. W.: Effect of calcium carbonate saturation of seawater on coral calcification, Global Planet. Change, 18, 37-46, doi:10.1016/S0921-8181(98)00035-6, 1998.

Geider, R., MacIntyre, H., and Kana, T.: Dynamic model of phytoplankton growth and acclimation: responses of the balanced growth rate and the chlorophyll a: carbon ratio to light, nutrientlimitation and temperature, Mar. Ecol.-Prog. Ser. 148, 187-200, 1997.

Gilchrist, G. W.: Specialists and generalists in changing environments .1. fitness landscapes of thermal sensitivity, Am. Nat., 146, 252-270, doi:10.1086/285797, 1995.

Guinotte, J. M., Buddemeier, R. W., and Kleypas, J. A.: Future coral reef habitat marginality: temporal and spatial effects of climate change in the Pacific basin, Coral Reefs, 22, 551-558, doi:10.1007/s00338-003-0331-4, 2003.

Gustafsson, M. S., Baird, M. E., and Ralph, P. J.: The interchangeability of autotrophic and heterotrophic nitrogen sources in Scleractinian coral symbiotic relationships: A numerical study, Ecol. Model., 250, 183-194, 2013.

Halford, A. R. and Caley, M. J.: Towards an understanding of resilience in isolated coral reefs, Glob. Change Biol., 15, 30313045, doi:10.1111/j.1365-2486.2009.01972.x, 2009.

Hennige, S. J., Smith, D. J., Perkins, R., Consalvey, M., Paterson, D. M., and Suggett, D. J.: Photoacclimation, growth and distribution of massive coral species in clear and turbid waters, Mar. Ecol.Prog. Ser., 369, 77-88, 2008.

Hoegh-Guldberg, O., Mumby, P. J., Hooten, A. J., Steneck, R. S., Greenfield, P., Gomez, E., Harvell, C. D., Sale, P. F., Edwards, A. J., Caldeira, K., Knowlton, N., Eakin, C. M., Iglesias-Prieto, R., Muthiga, N., Bradbury, R. H., Dubi, A., and Hatziolos, M. E.: Coral reefs under rapid climate change and ocean acidification, Science, 318, 1737-1742, doi:10.1126/Science.1152509, 2007.

Hoeke, R. K., Jokiel, P. L., Buddemeier, R. W., and Brainard, R. E.: Projected changes to growth and mortality of Hawaiian corals over the next 100 years, Plos One, 6, e18038, doi:10.1371/journal.pone.0018038, 2011.

Holcomb, M., Cohen, A. L., and McCorkle, D. C.: An investigation of the calcification response of the scleractinian coral Astrangia poculata to elevated $p \mathrm{CO}_{2}$ and the effects of nutrients, zooxanthellae and gender, Biogeosciences, 9, 29-39, doi:10.5194/bg-929-2012, 2012.

Houlbreque, F. and Ferrier-Pages, C.: Heterotrophy in tropical scleractinian corals, Biol. Rev. Camb. Philos., 84, 1-17, doi:10.1111/j.1469-185X.2008.00058.x, 2009.

Howells, E., Berkelmans, R., Van Oppen, M., Willis, B. L., and Bay, L.: Historical thermal regimes define limits to coral acclimatisation, Ecology, 94, 1078-1088, doi:10.1890/12-1257.1, 2013.

IPCC: Climate Change 2014: Impacts, Adaptation, and Vulnerability, Part A: Global and Sectoral Aspects, Contribution of Working Group II to the Fifth Assessment Report of the Intergovern- 
mental Panel on Climate Change, Cambridge University Press, Cambridge, United Kingdom and New York, 2014.

Jokiel, P: The reef coral two compartment proton flux model A new approach relating tissue-level physiological processes to gross corallum morphology, J. Exp. Mar. Biol. Ecol., 409, 1-12, doi:10.1016/j.jembe.2011.10.008, 2011.

Jokiel, P. L. and Coles, S. L.: Effects of temperature on mortality and growth of Hawaiian reef corals, Mar. Biol., 43, 201-208, doi:10.1007/Bf00402312, 1977.

Jokiel, P. L. and Guinther, E. B.: Effects of temperature on reproduction in the hermatypic coral Pocillopora damicornis, B. Mar. Sci., 28, 786-789, 1978.

Jokiel, P. L., Jury, C. P., and Rodgers, K. S.: Coral-algae metabolism and diurnal changes in the $\mathrm{CO}_{2}$-carbonate system of bulk sea water, PeerJ, 2, e378, doi:10.7717/peerj.378, 2014.

Jones, R. J., Hoegh-Guldberg, O., Larkum, A. W. D., and Schreiber, U.: Temperature-induced bleaching of corals begins with impairment of the $\mathrm{CO}_{2}$ fixation mechanism in zooxanthellae, Plant Cell Environ., 21, 1219-1230, doi:10.1046/J.13653040.1998.00345.X, 1998.

Key, R. M., Kozyr, A., Sabine, C. L., Lee, K., Wanninkhof, R., Bullister, J., Feely, R. A., Millero, F., Mordy, C., and Peng, T.H.: A global ocean carbon climatology: Results from Global Data Analysis Project (GLODAP), Global Biogeochem. Cy., 18, GB4031, doi:10.1029/2004GB002247, 2004.

Kinzie III, R. A., Takayama, M, Santos, S. R. and Coffroth, M. A.: The adaptive bleaching hypothesis: Experimental tests of Critical Assumptions, Biol. Bull., 200, 51-58, 2001.

Kleypas, J. A. and Langdon, C.: Coral reefs and changing seawater carbonate chemistry, Coast. Estuar. Stud., 61, 73-110, 2006.

Kleypas, J. A, McManus, J. W., and Meñez, L. A. B.: Environmental Limits to Coral Reef Development: Where Do We Draw the Line?, Amer. Zool., 39, 146-159, doi:10.1093/icb/39.1.146, 1999.

Kuffner, I. B., Andersson, A. J., Jokiel, P. L., Rodgers, K. S., and Mackenzie, F. T.: Decreased abundance of crustose coralline algae due to ocean acidification, Nat. Geosci., 1, 114-117, 2008.

Langdon, $\mathrm{C}$. : Effect of elevated $\mathrm{pCO}_{2}$ on photosynthesis and calcification of corals and interactions with seasonal change in temperature/irradiance and nutrient enrichment, J. Geophys. Res., 110, C09S07, doi:10.1029/2004jc002576, 2005.

Leclercq, N., Gattuso, J. P., and Jaubert, J.: $\mathrm{CO}_{2}$ partial pressure controls the calcification rate of a coral community, Glob. Change Biol., 6, 329-334, doi:10.1046/J.13652486.2000.00315.X, 2000.

Leclercq, N., Gattuso, J. P., and Jaubert, J.: Primary production, respiration, and calcification of a coral reef mesocosm under increased $\mathrm{CO}_{2}$ partial pressure, Limnol. Oceanogr., 47, 558-564, 2002.

Lima, F. P. and Wethey, D. S.: Three decades of high-resolution coastal sea surface temperatures reveal more than warming, Nat. Commun., 3, 704, doi:10.1038/ncomms1713, 2012.

Le Quéré, C., Andres, R. J., Boden, T., Conway, T., Houghton, R. A., House, J. I., Marland, G., Peters, G. P., van der Werf, G. R., Ahlström, A., Andrew, R. M., Bopp, L., Canadell, J. G., Ciais, P., Doney, S. C., Enright, C., Friedlingstein, P., Huntingford, C., Jain, A. K., Jourdain, C., Kato, E., Keeling, R. F., Klein Goldewijk, K., Levis, S., Levy, P., Lomas, M., Poulter, B., Raupach, M. R., Schwinger, J., Sitch, S., Stocker, B. D., Viovy, N., Zaehle,
S., and Zeng, N.: The global carbon budget 1959-2011, Earth Syst. Sci. Data, 5, 165-185, doi:10.5194/essd-5-165-2013, 2013.

Lough, J. and Barnes, D.: Several centuries of variation in skeletal extension, density and calcification in massive Porites colonies from the Great Barrier Reef: A proxy for seawater temperature and a background of variability against which to identify unnatural change, J. Exp. Mar. Biol. Ecol., 211, 29-67, 1997.

Lough, J. and Barnes, D.: Environmental controls on growth of the massive coral Porites, J. Exp. Mar. Biol. Ecol., 245, 225-243, 2000.

Lough, J. M.: Coral calcification from skeletal records revisited, Mar. Ecol.-Prog. Ser., 373, 257-264, doi:10.3354/Meps07398, 2008.

Lough, J. M.: Small change, big difference: sea surface temperature distributions for tropical coral reef ecosystems, 1950-2011, J Geophys. Res., 117, C09018, doi:10.1029/2012JC008199, 2012.

Marshall, P. and Baird, A.: Bleaching of corals on the Great Barrier Reef: differential susceptibilities among taxa, Coral Reefs, 19, 155-163, 2000.

Marshall, A. T. and Clode, P.: Calcification rate and the effect of temperature in a zooxanthellate and an azooxanthellate scleractinian reef coral, Coral Reefs, 23, 218-224, 2004.

Marubini, F., Barnett, H., Langdon, C., and Atkinson, M. J.: Dependence of calcification on light and carbonate ion concentration for the hermatypic coral Porites compressa, Mar. Ecol.-Prog. Ser., 220, 153-162, doi:10.3354/Meps220153, 2001.

Marubini, F., Ferrier-Pagès, C., Furla, P., and Allemand, D.: Coral calcification responds to seawater acidification: a working hypothesis towards a physiological mechanism, Coral Reefs, 27, 491-499, doi:10.1007/s00338-008-0375-6, 2008.

Mass, T., Einbinder, S., Brokovich, E., Shashar, N., Vago, R., Erez, J., and Dubinsky, Z.: Photoacclimation of Stylophora pistillata to light extremes: metabolism and calcification, Mar. Ecol.-Prog. Ser., 334, 93-102, 2007.

Muller, E. B., Kooijman, S. A., Edmunds, P. J., Doyle, F. J., and Nisbet, R. M.: Dynamic energy budgets in syntrophic symbiotic relationships between heterotrophic hosts and photoautotrophic symbionts, J. Theor. Biol., 259, 44-57, 2009.

Nisbet, R. M., Muller, E. B., Lika, K., and Kooijman, S. A. L. M.: From molecules to ecosystems through dynamic energy budget models, J. Anim. Ecol., 69, 913-926, doi:10.1046/J.13652656.2000.00448.X, 2000.

Ohde, S. and Hossain, M. M. M.: Effect of $\mathrm{CaCO}_{3}$ (aragonite) saturation state of seawater on calcification of Porites coral, Geochem. J., 38, 613-621, 2004.

Pandolfi, J. M., Connolly, S. R., Marshall, D. J., and Cohen, A. L.: Projecting coral reef futures under global warming and ocean acidification, Science, 333, 418-422, doi:10.1126/science.1204794, 2011.

Porter, J., Muscatine, L., Dubinsky, Z., and Falkowski, P.: Primary production and photoadaptation in light-and shade-adapted colonies of the symbiotic coral, Stylophora pistillata, P. Roy. Soc. Lond. B Bio., 222, 161-180, 1984.

Poulsen, A., Burns, K., Lough, J., Brinkman, D., and Delean, S.: Trace analysis of hydrocarbons in coral cores from Saudi Arabia, Org. Geochem., 37, 1913-1930, doi:10.1016/J.Orggeochem.2006.07.011, 2006.

Putron, S. J., McCorkle, D. C., Cohen, A. L., and Dillon, A. B.: The impact of seawater saturation state and bicarbonate 
ion concentration on calcification by new recruits of two Atlantic corals, Coral Reefs, 30, 321-328, doi:10.1007/s00338010-0697-z, 2010.

Rayner, N., Parker, D., Horton, E., Folland, C., Alexander, L., Rowell, D., Kent, E., and Kaplan, A.: Global analyses of sea surface temperature, sea ice, and night marine air temperature since the late nineteenth century, J. Geophys. Res.-Atmos. (1984-2012), 108, 4407, doi:10.1029/2002JD002670, 2003.

Reynolds, R. W., Smith, T. M., Liu, C., Chelton, D. B., Casey, K. S., and Schlax, M. G.: Daily high-resolution-blended analyses for sea surface temperature, J. Climate, 20, 5473-5496, doi:10.1175/2007jcli1824.1, 2007.

Ricke, K. L., Orr, J. C., Schneider, K., and Caldeira, K.: Risks to coral reefs from ocean carbonate chemistry changes in recent earth system model projections, Environ. Res. Lett., 8, 034003, doi:10.1088/1748-9326/8/3/034003, 2013.

Ries, J. B., Cohen, A. L., and McCorkle, D. C.: A nonlinear calcification response to $\mathrm{CO}_{2}$-induced ocean acidification by the coral Oculina arbuscula, Coral Reefs, 29, 661-674, doi:10.1007/s00338-010-0632-3, 2010.

Rodrigues, L. J. and Grottoli, A. G.: Calcification rate and the stable carbon, oxygen, and nitrogen isotopes in the skeleton, host tissue, and zooxanthellae of bleached and recovering Hawaiian corals, Geochim. Cosmochim. Ac., 70, 2781-2789, doi:10.1016/j.gca.2006.02.014, 2006.

Schneider, K. and Erez, J.: The effect of carbonate chemistry on calcification and photosynthesis in the hermatypic coral Acropora eurystoma, Limnol. Oceanogr., 51, 1284-1293, 2006.

Scoffin, T., Tudhope, A., Brown, B., Chansang, H., and Cheeney, R.: Patterns and possible environmental controls of skeletogenesis of Porites lutea, South Thailand, Coral Reefs, 11, 1-11, 1992.

Shamberger, K. E. F, Feely, R. A, Sabine, C. L, Atkinson, M. J., DeCarlo, E. H., Mackenzie, F. T, Drupp, P. S., and Butterfield, D. A.: Calcification and organic production on a Hawaiian coral reef, Mar. Chem., 127, 64-75, doi:10.1016/j.marchem.2011.08.003, 2011.

Shamberger, K. E. F., Cohen, A. L., Golbuu, Y., McCorkle, D. C., Lentz, S. J., and Barkley, H. C.: Diverse coral communities in naturally acidified waters of a Western Pacific Reef, Geophys. Res. Lett., 41, 499-504, doi:10.1002/2013GL058489, 2014.
Shaw, E. C., McNeil, B. I., and Tilbrook, B.: Impacts of ocean acidification in naturally variable coral reef flat ecosystems, J. Geophys. Res., 117, C03038, doi:10.1029/2011jc007655, 2012.

Shi, Q., Yu, K. F., Chen, T. R., Zhang, H. L., Zhao, M. X., and Yan, H. Q.: Two centuries-long records of skeletal calcification in massive Porites colonies from Meiji Reef in the southern South China Sea and its responses to atmospheric $\mathrm{CO}_{2}$ and seawater temperature, Sci. China Earth Sci., 55, 1-12, doi:10.1007/S11430-011-4320-0, 2012.

Silverman, J., Lazar, B., Cao, L., Caldeira, K., and Erez, J.: Coral reefs may start dissolving when atmospheric $\mathrm{CO}_{2}$ doubles, Geophys. Res. Lett., 36, L05606, doi:10.1029/2008g1036282, 2009.

Stearns, S. C.: The evolutionary significance of phenotypic plasticity, Bioscience, 39, 436-445, 1998.

Stephens, C., Antonov, J. I., Boyer, T. P., Conkright, M. E., Locarnini, R. A., O'Brien, T. D., and Garcia, H. E.: World Ocean Atlas 2001, Volume 1: Temperature, edited by: Levitus, S., NOAA Atlas NESDIS 49, U.S. Government Printing Office, Wash., D.C., 167 pp., CD-ROMs, 2002.

Thornhill, D. J., Rotjan, R. D., Todd, B. D., Chilcoat, G. C., Iglesias-Prieto, R., Kemp, D. W., LaJeunesse, T. C., Reynolds, J., Schmidt, G. W., Shannon, T., Warner, M. E., and Fitt, W. K.: A connection between colony biomass and death in Caribbean reef-building corals, PLoS ONE, 6, e29535, doi:10.1371/journal.pone.0029535, 2011.

van Hooidonk, R., Maynard, J. A., and Planes, S.: Temporary refugia for coral reefs in a warming world, Nature Climate Change, 3, 503-511, doi:10.1038/nclimate1829, 2013.

Venn, A. A., Tambutté, E., Holcomb, M., Laurent J., Allemand, D. and Tambutté, S., Impact of seawater acidification on $\mathrm{pH}$ at the tissue-skeleton interface and calcification in reef corals, P. Natl. Acad. Sci., 110, 5, 1634-1639, 2013.

Wilkinson, C.: Status of the coral reefs of the world, Global Coral Reef Monitoring Network and Reef And Rainforest Research Centre, Townsville, Australia, 296, 304 pp., 2008. 